\title{
Synthesis, structural, optical and magnetic properties of NiFe204/MWCNTs/ZnO hybrid nanocomposite for solar radiation driven photocatalytic degradation and magnetic separation
}

F. A. Hezam, Omer Nur and M. A. Mustafa

The self-archived postprint version of this journal article is available at Linköping University Institutional Repository (DiVA):

http://urn.kb.se/resolve?urn=urn:nbn:se:liu:diva-165159

N.B.: When citing this work, cite the original publication.

Hezam, F. A., Nur, O., Mustafa, M. A., (2020), Synthesis, structural, optical and magnetic properties of $\mathrm{NiFe2O} 4 / \mathrm{MWCNTs} / \mathrm{ZnO}$ hybrid nanocomposite for solar radiation driven photocatalytic degradation and magnetic separation, Colloids and Surfaces A, 592, 124586.

https://doi.org/10.1016/j.colsurfa.2020.124586

Original publication available at:

https://doi.org/10.1016/j.colsurfa.2020.124586

Copyright: Elsevier

http://www.elsevier.com/

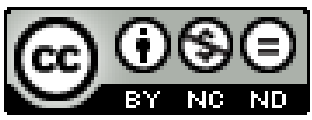




\title{
Synthesis, structural, optical and magnetic properties of $\mathrm{NiFe}_{2} \mathrm{O}_{4} / \mathrm{MWCNTs} / \mathrm{ZnO}$ hybrid nanocomposite for solar radiation driven photocatalytic degradation and magnetic separation
}

\author{
F. A. Hezam ${ }^{\text {a, b }}$, O. Nur ${ }^{\text {c }}$, M. A. Mustafa ${ }^{\text {d,* }}$ \\ ${ }^{a}$ Department of Physics, Taiz University, 9674 Taiz, Yemen \\ ${ }^{\mathrm{b}}$ Department of Physics, University of Khartoum, 11115 Khartoum, Sudan \\ ${ }^{\mathrm{c}}$ Department of Science and Technology, Campus Norrköping, Linköping University, SE-601 74 Norrköping Sweden \\ ${ }^{\mathrm{d}}$ Materials and Nanotechnology Research Centre, Department of Chemical Engineering, University of Khartoum, 11115 \\ Khartoum, Sudan
}

\begin{abstract}
Novel multifunctional $\mathrm{NiFe}_{2} \mathrm{O}_{4} / \mathrm{MWCNTs} / \mathrm{ZnO}$ hybrid nanocomposite has been successfully synthesized via the hydrothermal and the co-precipitation methods at $210{ }^{\circ} \mathrm{C}$ and $90{ }^{\circ} \mathrm{C}$, respectively, to be used as a solar radiation driven photocatalytic material. The hybrid nanocomposite exhibits enhanced photocatalytic activity compared to $\mathrm{NiFe}_{2} \mathrm{O}_{4}$ and $\mathrm{ZnO}$ for decolorization of Methylene Blue (MB) dye as a model pollutant- from aqueous solutions under solar radiation. Different complementary analytical tools were used to investigate the structural, optical and magnetic properties of the photocatalyst which possess good light response ability, photocatalytic stability, magnetic separation performance and reproducibility. The results from optical degradation confirmed the synergistic effect between the $\mathrm{NiFe}_{2} \mathrm{O}_{4}$, the $\mathrm{ZnO}$ and the MWCNTs. Suppressed recombination of electron-hole pairs mean more efficient charge separation and enhanced photocatalytic activity. The apparent rate constant $\left(k_{\text {app }}\right)$ of the MB decolorization for a duration of 300 minutes using $\mathrm{NiFe}_{2} \mathrm{O}_{4} / \mathrm{MWCNTs} / \mathrm{ZnO}, \mathrm{NiFe}_{2} \mathrm{O}_{4}$ and $\mathrm{ZnO}$ photocatalysts were found to be $0.00438 \mathrm{~min}^{-1}, 4.12857 \mathrm{E}^{-4} \mathrm{~min}^{-1}$ and $0.002 \mathrm{~min}^{-1}$, respectively. The removal efficiency was also investigated for different $\mathrm{pH}$ values. Due to the magnetic properties of the nanocomposite, it was possible to separate it after degradation experiments and hence re-usability is possible. In view of the enhanced solar radiation driven photodegradation, the present composite can present a robust alternative as a solar radiation driven photocatalyst.
\end{abstract}

Key words: Magnetic carbon nanotubes (Mag-CNTs); $\mathrm{NiFe}_{2} \mathrm{O}_{4}$ nanoparticles; Photocatalytic degradation, Magnetic separation.

"Corresponding author: Dr. M. A. Mustafa; Email: dr.mustafa.abbas@gmail.com. 


\section{Introduction}

The process industry is developing at an extremely rapid pace however one of the great challenges faced are the environmental pollution effects [1-7]. Most synthetic dyes employed in textile, cosmetics and other products have high contents of colored components, salts, organic contaminants and high chemical oxygen demand. They cannot be eliminated efficiently by conventional chemical oxidation and traditional biodegradation methods due to their stable complicated aromatic molecules [8]. Carbon nanotubes (CNTs) have been proven to acquire a great potential as a superior adsorbent for eliminating many kinds of inorganic and organic pollutants from aqueous solutions, due to their small pore size, large specific surface area, hollow and layered structures [9]. Functionalization of the CNTs surface with different materials like polymers, metals, metal oxides and complex metal oxides can develop CNTs features and will possess potential applications as magnetic data storage [10], electric devices [11] and heterogeneous catalysis [12].

It is believed that a remarkable improvement of the photocatalytic activity can be achieved via the combination of CNTs and a suitable semiconductor due to the synergistic effect [13-16]. The semiconductors alone display some photocatalytic effect, but the limitations diminish their wider applicability. The anchoring of semiconductors with multi-walled carbon nanotubes (MWCNTs), overcome such limitations and make semiconductor composites better photocatalyst materials [17].

Among the many semiconductors used in the field of photocatalysis are $\mathrm{TiO}_{2}, \mathrm{ZnO}$ and $\mathrm{CdS}$ [18-23]. ZnO is widely used in photocatalytic degradation of organic pollutants [7]. It is well known as an excellent photocatalyst due to its superior features such as non-toxicity, lower cost synthesis possibilities and chemical stability [24, 25]. Most semiconductors basically absorb ultraviolet light [26, 27] which accounts for only $3 \%-5 \%$ of sunlight [19]. ZnO has a wide band gap $(\sim 3.37 \mathrm{eV})[7,28]$, which is unfavorable for the absorption of solar visible light. However, $\mathrm{ZnO}$ possesses point defects that fills the band gap and enable the emission and absorption of the light energy in the visible range. To further improve the $\mathrm{ZnO}$ performance, several attempts have been made to increase the shift of its absorption band from UV to the visible light region by different approaches such as e.g. doping or coupling $\mathrm{ZnO}$ with metals, nonmetals, and metal oxides. The difficulty in isolating the $\mathrm{ZnO}$ and CNTs based photocatalysts from aqueous solutions after usage limits their application in treatment of water polluted with dyes [24]. Although centrifugation, precipitation, filtration and other methods have been used to separate the photocatalysts from the reaction solution, the separation process is generally complex and time-consuming. Therefore, to solve the problem, and in order to separate the 
photocatalysts conveniently after the reaction, magnetic carriers are introduced into the photocatalyst to prepare a good recyclable magnetic photocatalyst, for example, coupling of ZnO or CNTs with strong magnetic materials as spinal ferrites [29]. This is an alternative option for isolation by filtration or centrifugation [13, 30]. Furthermore, decoration of CNTs by spinel ferrites nanoparticles (NPs) which are very important magnetic materials, can improve the optical, electrochemical and magnetic properties

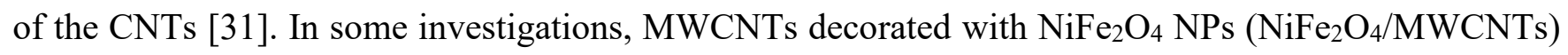
have proven to be an appropriate mediator in electrochemical processes [32]. Previous studies have clearly demonstrated that the synergistic effect through the decoration of CNTs by $\mathrm{NiFe}_{2} \mathrm{O}_{4}$ can improve the optical, electrochemical and magnetic properties of the CNTs $[13,33]$. It is clearly demonstrated that it is possible to further promote the activity of the photoinduced charge separation leading to high photocatalytic efficiency due to the synergistic effect through the combination of $\mathrm{ZnO}$ [34-36] or $\mathrm{NiFe}_{2} \mathrm{O}_{4}[13,33,37]$ with CNTs to make hybrids for effective elimination of dye contaminants from aqueous solutions.

Likewise, coupling among $\mathrm{ZnO}$ and $\mathrm{NiFe}_{2} \mathrm{O}_{4}$ creates a semiconductor photocatalyst which enhances the photocatalytic activity under visible light $[24,38]$. Theoretically, when ferrite composites are coupled with $\mathrm{ZnO}$, a heterojunction is created and then the photoinduced electrons and holes are separated effectively, give rise to enhancement in the photocatalytic efficiency [39]. Zhu et al. [38] used $\mathrm{NiFe}_{2} \mathrm{O}_{4} / \mathrm{ZnO}$ hybrid prepared by the hydrothermal method for Congo red (CR) dye removal by adsorption and photocatalysis, then the magnetic hybrid was easily and effectively separated from the aqueous solution by an external magnet. Jamarun et al. [24] used the solvothermal method to prepare the same composite for photocatalytic Rhodamine B dye degradation under solar light. The two previous studies i.e. [24] and [38] reported that the photocatalytic activity of the synthesized nanocomposites were higher than pristine $\mathrm{ZnO}$ and pristine $\mathrm{NiFe}_{2} \mathrm{O}_{4}$. Zhu et al. [13] used $\mathrm{NiFe}_{2} \mathrm{O}_{4} / \mathrm{MWCNTs}$ hybrid prepared by the hydrothermal method to investigate its photocatalytic activity for the removal of Congo red (CR) dye from aqueous solutions under simulated solar light irradiation. It was found that the activity was 2.18 times higher than that of $\mathrm{NiFe}_{2} \mathrm{O}_{4}$. Seffah et al. [40] synthesized the same nanocomposite by hydrolysis using refluxing for 45 minutes which have been used for the elimination of methyl orange dye from polluted water.

In this study, novel multifunctional $\mathrm{NiFe}_{2} \mathrm{O}_{4} / \mathrm{MWCNTs} / \mathrm{ZnO}$ photocatalyst has been synthesized via the hydrothermal and co-precipitation methods (two-steps process) and was investigated as an efficient visible light driven photocatalyst. The as-prepared composites were characterized using, UV- 
visible spectrometry, X-ray diffraction (XRD), Fourier transform infrared spectroscopy (FTIR), scanning electron microscope (SEM), energy dispersive x-ray spectroscopy (EDX), transmission electron microscope (TEM), Ultraviolet-visible diffuse reflectance spectroscopy (UV-Vis DRS), vibrating sample magnetometer (VSM) and electrochemical impedance spectroscopy (EIS).

\section{Materials and methods}

\subsection{Chemicals}

Multi-walled carbon nanotubes (+95\% Pure, Outer D: $30 \sim 50 \mathrm{~nm}$, Length: 10-30 $\mu \mathrm{m})$, were purchased from M K Impex Corp, (Mississauga, Ontario Canada). $\mathrm{Fe}\left(\mathrm{NO}_{3}\right)_{3} .9 \mathrm{H}_{2} \mathrm{O}, \mathrm{Ni}\left(\mathrm{NO}_{3}\right)_{2} \cdot 6 \mathrm{H}_{2} \mathrm{O}$, $\mathrm{Zn}\left(\mathrm{NO}_{3}\right)_{2} \cdot 6 \mathrm{H}_{2} \mathrm{O}$, Sodium Hydroxide $(\mathrm{NaOH})$ and Nitric acid $\left(\mathrm{HNO}_{3}, 65 \%\right)$ were obtained from $\mathrm{S} D$ Fine-CHEM Limited (SDFCL). All reagents were of analytical grade and were used without further purification. Methylene Blue (MB) dye was supplied by the National Center for Leather- Khartoum, Sudan.

\subsection{Oxidation of MWCNTs}

The MWCNTs were oxidized to facilitate good attachment with the other nano-materials such as $\mathrm{NiFe}_{2} \mathrm{O}_{4}$ NPs on its outer walls [41]. For oxidation of the MWCNTs, $0.5 \mathrm{~g}$ of pristine MWCNTs was sonicated in deionized water for 3 hours before adding them to a nitric acid solution (300 mL, 4 $\mathrm{mol} /$ liter) in an oil bath (refluxing at $110-120^{\circ} \mathrm{C}$ for 7 hours). The suspension was washed several times until the $\mathrm{pH}$ was neutral. Then they were dried for later usage.

\subsection{Preparation of $\mathrm{NiFe}_{2} \mathrm{O}_{4} / \mathrm{MWCNTs} / \mathrm{ZnO}$}

$\mathrm{NiFe}_{2} \mathrm{O}_{4} / \mathrm{MWCNTs} / \mathrm{ZnO}$ hybrid nanocomposite was prepared by the hydrothermal and the coprecipitation methods (Fig. 1). First $0.2 \mathrm{~g}$ of nitric acid treated MWCNTs was dispersed in $50 \mathrm{ml}$ deionized water. $1 \mathrm{~g}$ of $\mathrm{Ni}\left(\mathrm{NO}_{3}\right)_{2} \cdot 6 \mathrm{H}_{2} \mathrm{O}$ and $2 \mathrm{~g}$ of $\mathrm{Fe}\left(\mathrm{NO}_{3}\right)_{3} .9 \mathrm{H}_{2} \mathrm{O}$ were added slowly to the solution under vigorous stirring for 10 minutes to obtain a homogenous solution. The $\mathrm{pH}$ of the mixture was adjusted to13 by adding $\mathrm{NaOH}$ solution $(6 \mathrm{M})$ drop-wise. Then the solution was subjected to stirring for 20 minutes at room temperature. After that the mixture was transferred into a $100 \mathrm{~mL}$ Teflon-lined stainless steel autoclave and maintained at $210^{\circ} \mathrm{C}$ in an oil bath for 5 hours. After the container is left to cool naturally, the resulting precipitate was washed several times by deionized water. $\mathrm{NiFe}_{2} \mathrm{O}_{4} / \mathrm{MWCNTs}$ hybrid nanocomposite was then formed. 
In the next stage, the as-synthesized $\mathrm{NiFe}_{2} \mathrm{O}_{4} /$ MWCNTs (wet precipitate) was decorated on its outer surface by ZnO NPs using the co-precipitation method. In details, the resulting washed precipitate $\left(\mathrm{NiFe}_{2} \mathrm{O}_{4} / \mathrm{MWCNTs}\right.$ ) was added to a $350 \mathrm{ml}$ deionized water under vigorous stirring for 10 minutes. After that $3.2 \mathrm{~g}$ of $\mathrm{Zn}\left(\mathrm{NO}_{3}\right)_{2} \cdot 6 \mathrm{H}_{2} \mathrm{O}$ is dissolved in the solution for also 10 minutes, and then $\mathrm{NaOH}$ solution $(0.6 \mathrm{M})$ was added drop-wise to the solution until the precipitate appears when the color of the dark brown solution changes to be light brown, which means that zinc oxide NPs are achieved. Finally, the solution was heated at $70{ }^{\circ} \mathrm{C}$ for one hour, and then a $\mathrm{NiFe}_{2} \mathrm{O}_{4} / \mathrm{MWCNTs} / \mathrm{ZnO}$ hybrid nanocomposite is formed. It was then washed several times and dried for later usage. Pure $\mathrm{NiFe}_{2} \mathrm{O}_{4}$ nanocomposite was synthesized by the same way as the method used for the $\mathrm{NiFe}_{2} \mathrm{O}_{4} / \mathrm{MWCNTs}$ hybrid nanocomposite except that for the $\mathrm{NiFe}_{2} \mathrm{O}_{4}$ preparation, the Teflon-lined stainless-steel autoclave was kept 3 hours only in the oil bath.

During the hydrothermal operation, in the first step, the MWCNTs act as a substrate for the growth of the spinel ferrites because of the interaction between the $\mathrm{Ni}$, Fe precursors and the functional groups on the surface of the MWCNTs which covalently attach the molecules.

The mechanism for the formation of the $\mathrm{NiFe}_{2} \mathrm{O}_{4} / \mathrm{MWCNTs} / \mathrm{ZnO}$ nanocomposite is as follows: Firstly, the chemical treatment (oxidation) of the MWCNTs by the $\mathrm{HNO}_{3}$ acid introduced a considerable carboxyl groups on the outer walls of the MWCNTs as indicated by the FTIR results. The functional groups that are negatively charged make the MWCNTs active for interaction with metal ions. With introducing functionalized MWCNTs into the solution containing the metal salts, the $\mathrm{Ni}^{2+}$ and $\mathrm{Fe}^{3+}$ ions are attached by electrostatic interactions to the carboxylic groups that function as nucleation sites. Then, the $\mathrm{NaOH}$ reacts with the metal ions that precipitate down after converting them into metal hydroxides. After heating for one hour at $100{ }^{\circ} \mathrm{C}$, this precipitates is transformed into ferrite NPs. 

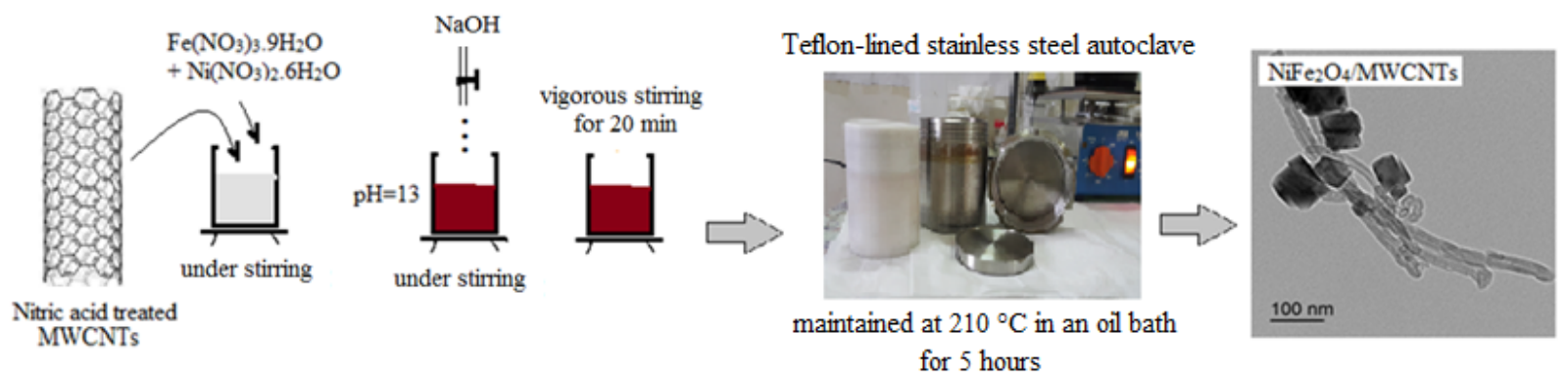

heating at $70^{\circ} \mathrm{C}$ for one hour
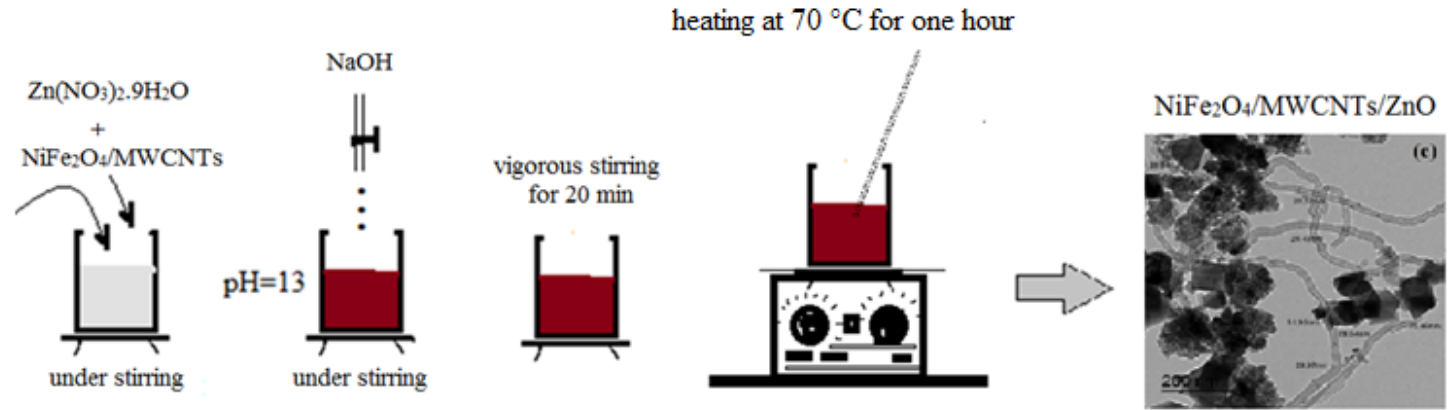

Fig. 1. Schematic diagram of the preparation of the $\mathrm{NiFe}_{2} \mathrm{O}_{4} / \mathrm{MWCNTs} / \mathrm{ZnO}$ hybrid nanocomposite.

\subsection{Characterization of the $\mathrm{NiFe}_{2} \mathrm{O}_{4} / \mathrm{MWCNTs} / \mathrm{ZnO}$}

XRD patterns of the composites were recorded using x-ray powder diffraction XRD7000S/7000L, SHIMADZU equipped with $\mathrm{Cu}_{\alpha, 1}(\lambda=1.5406 \AA$ ). UV-Vis diffuse reflectance spectrometer (DRS) Jasco-V-570, Japan was used to record the absorbance spectra of samples. UV-Vis spectrophotometer UV-1800, SHIMADZU was used to record the changes in the absorbance of the MB dye solution. The morphology was characterized using scanning electron microscopy (SEM) TESCAN MIRA 3 equipped with the energy dispersive spectroscopy analysis (EDS) attached part, and highresolution transmission electron microscopy (HR-TEM) JEM-2100, JEOL, Japan. Room temperature magnetic properties were measured using a vibrating sample magnetometer (VSM) 7410-Lake Shore, USA. Fourier transform infra-red (FTIR) spectra were recorded using a SHIMADZU 8400S FTIR spectrometer. Cole-Cole semicircles were performed using electrochemical impedance spectroscopy (EIS) at room temperature in a dry nitrogen atmosphere through Novocontrol turnkey concept 40 System in the frequency range from $0.1 \mathrm{~Hz}$ to $20 \mathrm{MHz}$. The specimens were scanned through sandwiching between two copper electrodes $(\mathrm{r}=0.5 \mathrm{~cm})$. 


\subsection{Photocatalytic experiments}

The activity of the $\mathrm{NiFe}_{2} \mathrm{O}_{4} / \mathrm{MWCNTs} / \mathrm{ZnO}$ photocatalyst was evaluated by photocatalytic decolorization of the MB dye under solar light irradiation at ambient temperature. All experiments were conducted with a constant catalyst dosage $\left(1.0 \mathrm{~g} \mathrm{~L}^{-1}\right)$ and constant initial dye concentration $\left(20 \mathrm{mg} \mathrm{L}^{-1}\right)$. Typically, $50 \mathrm{mg}$ of $\mathrm{NiFe}_{2} \mathrm{O}_{4} / \mathrm{MWCNTs} / \mathrm{ZnO}$ was added to $50 \mathrm{~mL}$ of $\mathrm{MB}$ dye solution. During the reaction, at given time intervals, $3 \mathrm{~mL}$ of solution was drawn and the catalyst was separated immediately by a magnet from the drawn solutions and the dye concentration was analyzed at $\lambda_{\max }=658 \mathrm{~nm}$ using UV-Visible spectrophotometer. Three repeated experiments were performed (the average was taken) made the experimental data more reliable. The decolorization efficiency $(\eta)(\%)$ of the MB dye by the photocatalyst at time $\mathrm{t}$ was calculated by the equation:

$$
\eta(\%)=\left(\left(C_{0}-C_{1}\right) / C_{0}\right) \times 100 \%
$$

taking $\mathrm{A}_{0}$ and $\mathrm{A}_{\mathrm{t}}$ to represent the absorbance of the $\mathrm{MB}$ dye solution before and after the solar light irradiation at any time $\mathrm{t}$, respectively, such that $A_{t} / A_{0}=C_{t} / C_{0}$, where $\mathrm{C}_{0}$ is the initial $\mathrm{MB}$ dye concentration $\left(\mathrm{mg} \mathrm{L}^{-1}\right)$ and $\mathrm{C}_{t}$ is the $\mathrm{MB}$ dye concentration $\left(\mathrm{mg} \mathrm{L}^{-1}\right)$ at any time $\mathrm{t}(\mathrm{min})$. The decolorization kinetics of MB dye solution have been further investigated. The photodegradation process was fitted for the pseudo-first-order kinetic model in order to describe the corresponding experimental data $[42,43]$ according to the following equation:

$$
\ln \left(C_{0} / C_{t}\right)=k_{\text {app }} t
$$

where " $\mathrm{t}$ " is the reaction time (minutes), $\mathrm{k}_{\mathrm{app}}$ is the apparent reaction rate constant $\left(\mathrm{min}^{-1}\right)$.

\subsubsection{Recycling experiments}

In the recycling experiments, after the initial photodegradation reaction, the remaining solids were recovered by the use of an external magnet and ultrasonically washed in ethanol for 30 min to remove the $\mathrm{MB}$ and other by-products. Afterward, the $\mathrm{NiFe}_{2} \mathrm{O}_{4} / \mathrm{MWCNTs} / \mathrm{ZnO}$ photocatalyst was rinsed three times with deionized water and ethanol. The reproducibility of the catalyst was investigated by repeating the process five times at the normal $\mathrm{pH}$ (of the $\mathrm{MB}$ dye solution) and at high $\mathrm{pH}$ (11.55).

\section{Results and discussion}

\subsection{Characterization of catalysts}




\subsubsection{Structural properties}

Fig. 2 shows the XRD patterns of the pure $\mathrm{NiFe}_{2} \mathrm{O}_{4}, \mathrm{MWCNTs}, \mathrm{ZnO}$ and $\mathrm{NiFe}_{2} \mathrm{O}_{4} / \mathrm{MWCNTs} / \mathrm{ZnO}$ nanocomposites. It shows that the characteristic XRD patterns of the $\mathrm{NiFe}_{2} \mathrm{O}_{4}$,

MWCNTs and $\mathrm{ZnO}$ are present in the $\mathrm{NiFe}_{2} \mathrm{O}_{4} / \mathrm{MWCNTs} / \mathrm{ZnO}$ nanocomposite pattern. The characteristic peaks at $2 \theta=26.08^{\circ}$ and $43.08^{\circ}$ are attributed to graphite structure belonging to the (002) and (100) planes of the MWCNTs $[33,44]$. The diffraction peaks of the $\mathrm{NiFe}_{2} \mathrm{O}_{4}$ sample are observed at $2 \theta=30.34^{\circ}, 35.74^{\circ}, 37.35^{\circ}, 43.43^{\circ}, 53.90^{\circ}, 57.46^{\circ}$ and $63.11^{\circ}$, which can be indexed to (220), (311), (222), (400), (422), (511) and (440) planes of the face centered cubic structure of $\mathrm{NiFe}_{2} \mathrm{O}_{4}$, respectively, space group Fd-3m, which is consistent with the JCPDS data file no. 54-0964 [45, 46]. The diffraction peaks of the $\mathrm{ZnO}$ sample are observed at $2 \theta=31.75^{\circ}, 34.45^{\circ}, 36.25^{\circ}, 47.6^{\circ}, 56.54^{\circ}, 62.86^{\circ}$, $66.18^{\circ}, 67.95^{\circ}$ and $69.08^{\circ}$, which correspond to the (100), (002), (101), (102), (110), (103), (200), (112) and (201) crystal planes of the hexagonal ZnO phase (JCPDS no. 79-0206) [24, 38, 47]. Fig. 2 shows that in the XRD pattern of the $\mathrm{NiFe}_{2} \mathrm{O}_{4} / \mathrm{MWCNTs} / \mathrm{ZnO}$ sample no other peak related to impurities was detected which further confirms that the synthesized nanocomposite is of high purity and having good crystallinity. The average crystallite size of the nanocomposites was calculated from the most intense reflection using Debye-Scherrer's formula [48]:

$$
D=0.89 \lambda /(B \cos \theta)
$$

where $\lambda=0.154056 \mathrm{~nm}, \mathrm{~B}$ : the full peak width at half maximum value, $\theta$ : the diffraction angle. The $\mathrm{NiFe}_{2} \mathrm{O}_{4}$ and the $\mathrm{ZnO}$ crystallite sizes were estimated to be $34.6 \mathrm{~nm}$ and $19.5 \mathrm{~nm}$, respectively. 

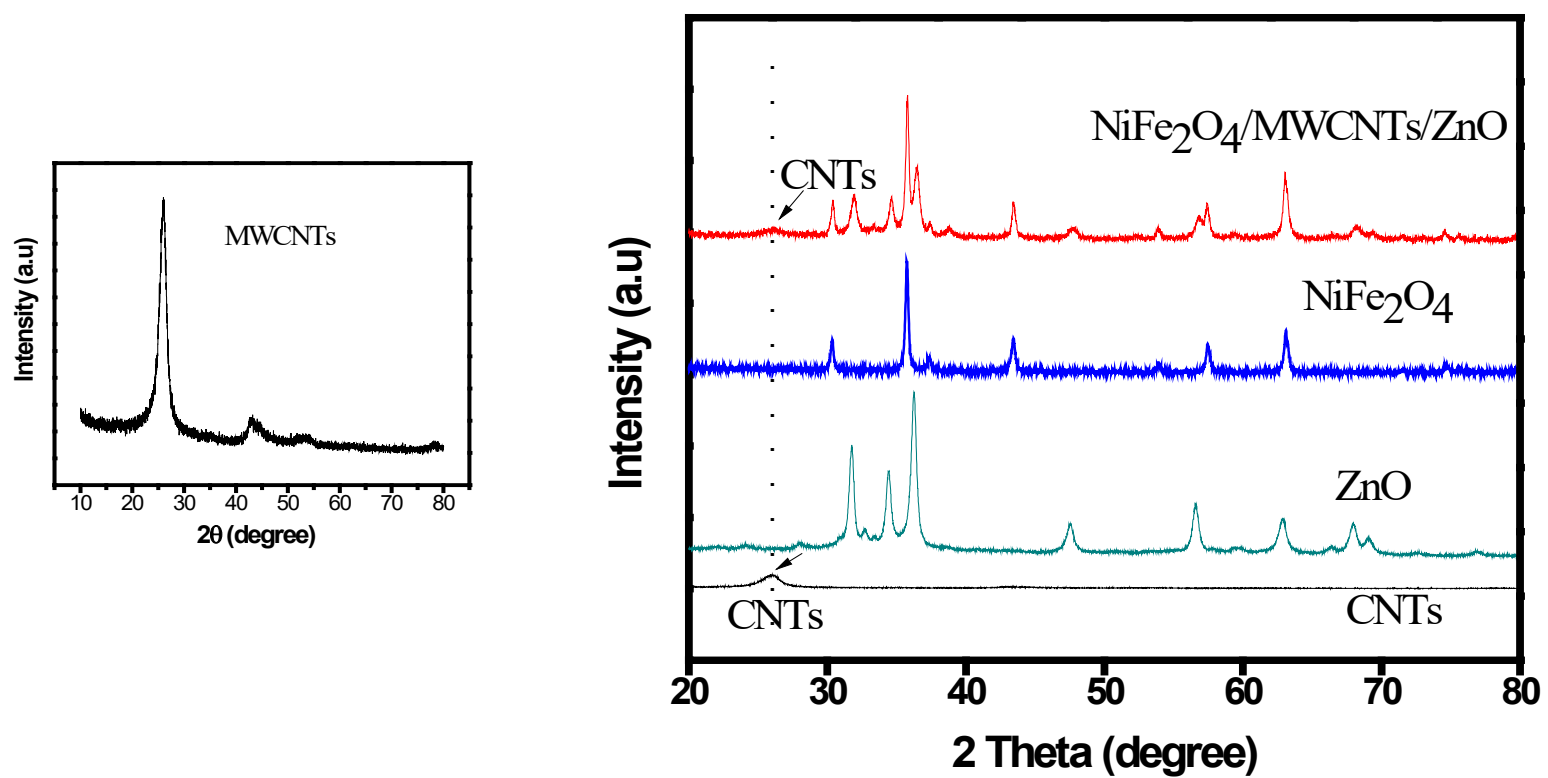

Fig. 2. XRD patterns of MWCNTs, $\mathrm{ZnO}, \mathrm{NiFe}_{2} \mathrm{O}_{4}$, and $\mathrm{NiFe}_{2} \mathrm{O}_{4} / \mathrm{MWCNTs} / \mathrm{ZnO}$ nanocomposites.

FTIR spectra (Fig. 3) were employed to further prove the formation of the above samples. The spectra of the raw and the oxidized MWCNTs are presented in Fig. 3(a) and the spectra of ZnO, $\mathrm{NiFe}_{2} \mathrm{O}_{4}$ and $\mathrm{NiFe}_{2} \mathrm{O}_{4} / \mathrm{MWCNTs} / \mathrm{ZnO}$ are presented in Fig. 3(b). For the raw MWCNTs, there are no significant bands except the sharp band around $1540 \mathrm{~cm}^{-1}$ corresponding to $\mathrm{C}=\mathrm{C}$ stretch vibration originating from the surface of the tubes [49] and at $3452 \mathrm{~cm}^{-1}$ corresponds to $\mathrm{O}-\mathrm{H}$ stretching vibrations of adsorbed water molecules [12]. As a result of the oxidation process of the MWCNTs, the bands in the area $1000-1300 \mathrm{~cm}^{-1}$ are attributed to $\mathrm{C}-\mathrm{O}$ bending frequencies [50-52]. The band around $1730 \mathrm{~cm}^{-1}$ are corresponding to $\mathrm{C}=\mathrm{O}$ stretch vibration $[53,54]$. Also, the bands between $2850-3000 \mathrm{~cm}^{-1}$ correspond to the $\mathrm{C}-\mathrm{H}$ stretching vibrations. This indicate that the $-\mathrm{COOH}$ group have been successfully introduced on the outer walls of the MWCNTs which make them active to attaching covalently with the decorated molecules.

Metal ions in ferrites are situated in two different sub-lattices designated as tetrahedral and octahedral according to the oxygen nearest neighbor's geometrical configuration. It has been reported that the band in the high frequency range from 650 to $550 \mathrm{~cm}^{-1}$ is related to the tetrahedral A-site, while the band in the low frequency range from 450 to $385 \mathrm{~cm}^{-1}$ is related to the octahedral B-site $[55,56]$. In Fig. 3(b), the sharp peaks at $601 \mathrm{~cm}^{-1}$ and $417 \mathrm{~cm}^{-1}$ correspond to the intrinsic vibrations of tetrahedral and octahedral metal-O bounds, respectively. The peak in the area around $400-500 \mathrm{~cm}^{-1}$ is assigned to 
the $\mathrm{Zn}-\mathrm{O}$ vibration [57], while the combination of the ferrite and the $\mathrm{ZnO}$ peaks appears at around 601 $\mathrm{cm}^{-1}$ [24]. The weaker band in the area $1100-1300 \mathrm{~cm}^{-1}$ corresponds to the vibration of the $\mathrm{NO}_{3}$ ions which are generated during the preparation and appeared with a very less intensity [58].
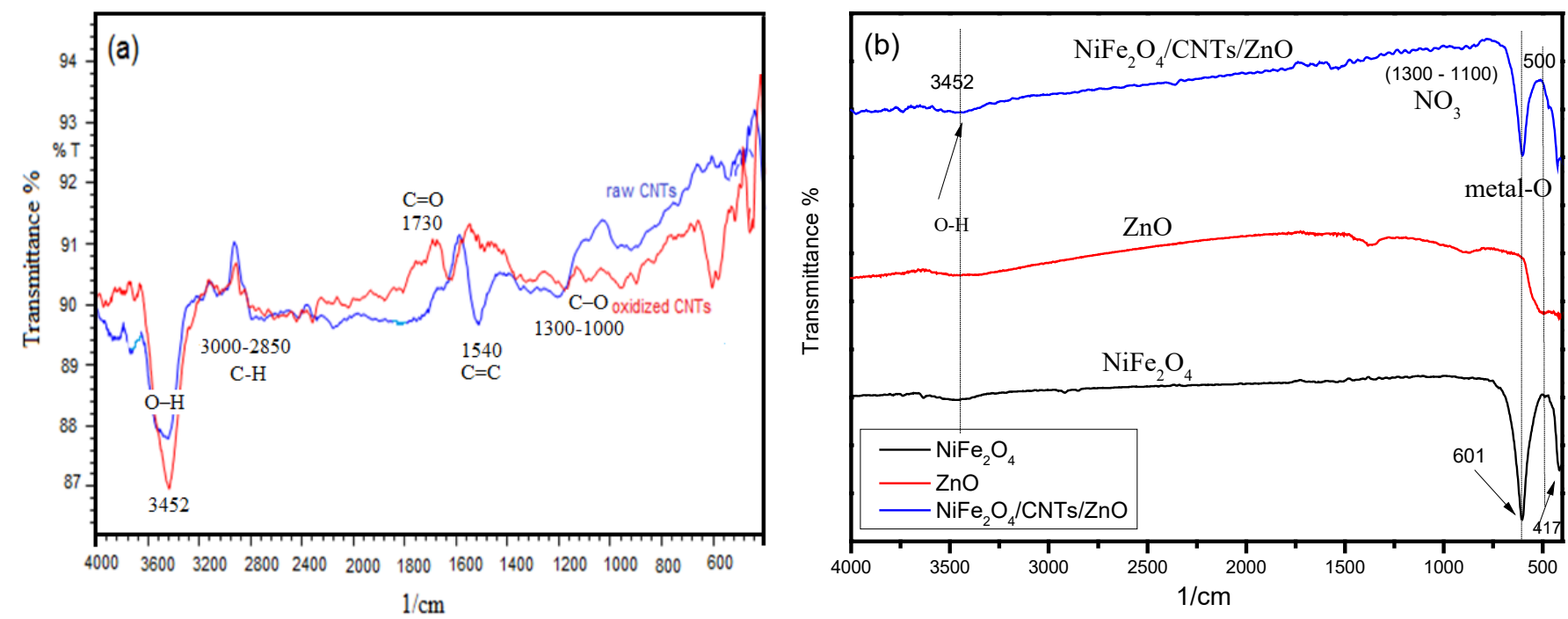

Fig. 3. FTIR spectrum of: (a) Pristine and oxidized MWCNTs, (b) $\mathrm{ZnO}, \mathrm{NiFe}_{2} \mathrm{O}_{4}$ and $\mathrm{NiFe}_{2} \mathrm{O}_{4} / \mathrm{MWCNTs} / \mathrm{ZnO}$ prepared nanocomposites.

\subsubsection{Morphology and composition}

The morphology of the samples was studied using SEM, EDX and TEM as shown in Figs. 4, 5 and 6. Fig. 4 (a-d) shows the pure $\mathrm{NiFe}_{2} \mathrm{O}_{4}$ and $\mathrm{ZnO}$ prepared NPs, and raw MWCNTs appear in the part e. The NPs sizes are estimated from the TEM images and were found to be in the nanoscale. As can be seen in Fig. 5, the surface of the MWCNTs is successfully decorated with the $\mathrm{NiFe}_{2} \mathrm{O}_{4}$ and the $\mathrm{ZnO}$ NPs. The $\mathrm{NiFe}_{2} \mathrm{O}_{4}$ and the $\mathrm{ZnO}$ NPs are bound as a hybrid and decorated the surface of the MWCNTs leading to the creation of the interaction between the $\mathrm{NiFe}_{2} \mathrm{O}_{4}$ and the $\mathrm{ZnO}$ NPs with each other and between them and the MWCNTs. The $\mathrm{NiFe}_{2} \mathrm{O}_{4}$ in the hybrid is much bigger than the ZnO NPs and the sizes of both pure $\mathrm{NiFe}_{2} \mathrm{O}_{4}$ and $\mathrm{ZnO}$ are smaller in the hybrid. The average size of the $\mathrm{NiFe}_{2} \mathrm{O}_{4} \mathrm{NPs}_{\text {s }}$ the surface of the MWCNTs is about $50 \mathrm{~nm}$ which is smaller than that of pure $\mathrm{NiFe}_{2} \mathrm{O}_{4} \mathrm{NPs}_{\text {(Figs. 4, and }}$ 5) indicating that the existence of MWCNTs has led to the crystallization of $\mathrm{NiFe}_{2} \mathrm{O}_{4}$ and $\mathrm{ZnO} \mathrm{NPs}$ with smaller sizes. Hence, the introduction of MWCNTs as a good support will make the loaded $\mathrm{NiFe}_{2} \mathrm{O}_{4}$ and $\mathrm{ZnO}$ achieve a further enhancement of the charge separation and suppressing the electron-hole recombination in photocatalytic processes [13]. The elemental mapping images and EDS spectra (Fig. 6) 
were also inspected and displayed. The sample contains $\mathrm{O}, \mathrm{Fe}, \mathrm{Ni}, \mathrm{Zn}, \mathrm{C}$ elements, further indicating that $\mathrm{NiFe}_{2} \mathrm{O}_{4} / \mathrm{MWCNTs} / \mathrm{ZnO}$ nanocomposite is successfully prepared.

The work in ref. [13]is the most close example to our present study where a novel $\mathrm{NiFe}_{2} \mathrm{O}_{4} / \mathrm{MWCNTs}$ hybrid nanocomposite has been synthesized via the hydrothermal method to remove the CR dye from its solutions using solar radiation time of 300 minutes reaching an efficiency of up to $90 \%$. We can observe the formation of $\mathrm{NiFe}_{2} \mathrm{O}_{4} \mathrm{NPs}$ in a larger size compared to the sizes formed on the surface of CNTs in this work and the morphology was similar to the mixture. That is due to the nature of the formation of the $\mathrm{NiFe}_{2} \mathrm{O}_{4} \mathrm{NPs}$, which are formed in large sizes compared to e.g. $\mathrm{Fe}_{3} \mathrm{O}_{4}$ ferrite which is formed in smaller sizes, thus allowing for homogeneous decoration of the entire surface of the MWCNTs.

In this work, the defects that we have seen in the morphology were due to the relatively short time applied in the MWCNTs treatment (only 7 hours). Since the treatment process (oxidation) of the pristine MWCNTs is the first essential step to the success of any functionalization process for the carbon nanotube surface, the time required for efficient processing must be longer. 

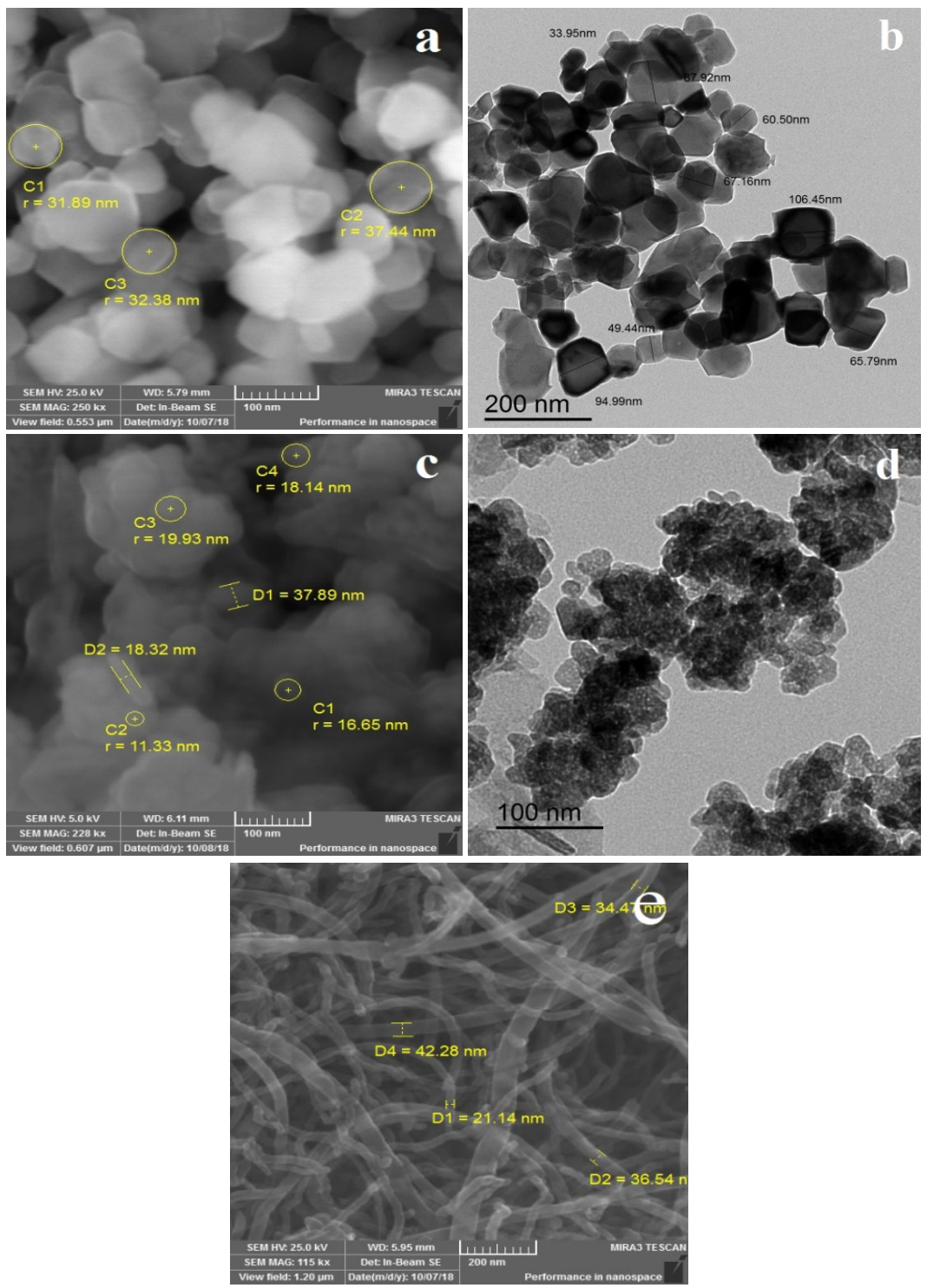

Fig. 4. (a), (b) SEM and TEM images of $\mathrm{NiFe}_{2} \mathrm{O}_{4}$ nanoparticles, respectively. (c), (d) SEM and TEM images of $\mathrm{ZnO}$ nanoparticles, respectively, and (e) SEM image of raw MWCNTs.
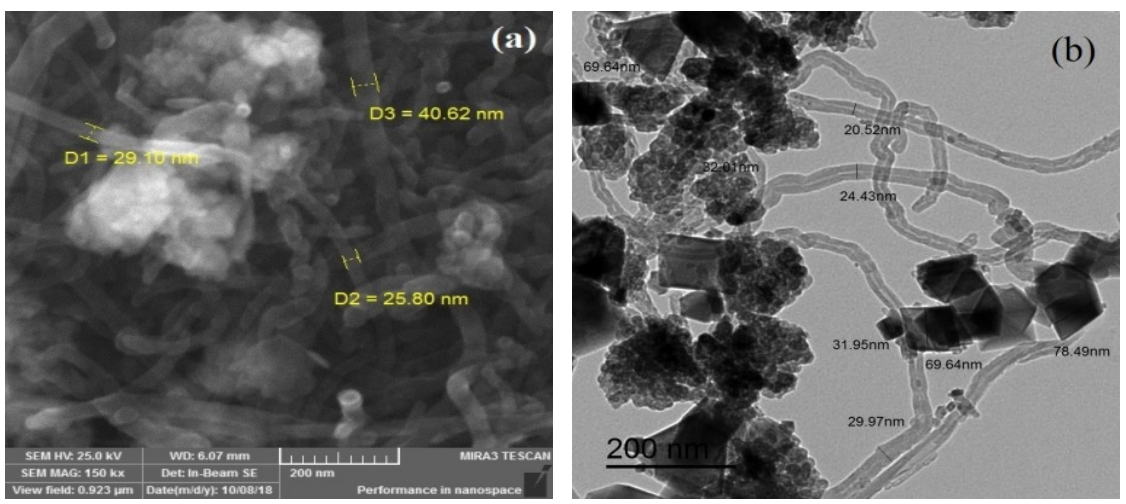

Fig. 5. (a) SEM, and (b) TEM images of $\mathrm{NiFe}_{2} \mathrm{O}_{4} / \mathrm{MWCNTs} / \mathrm{ZnO}$ nanocomposite. 


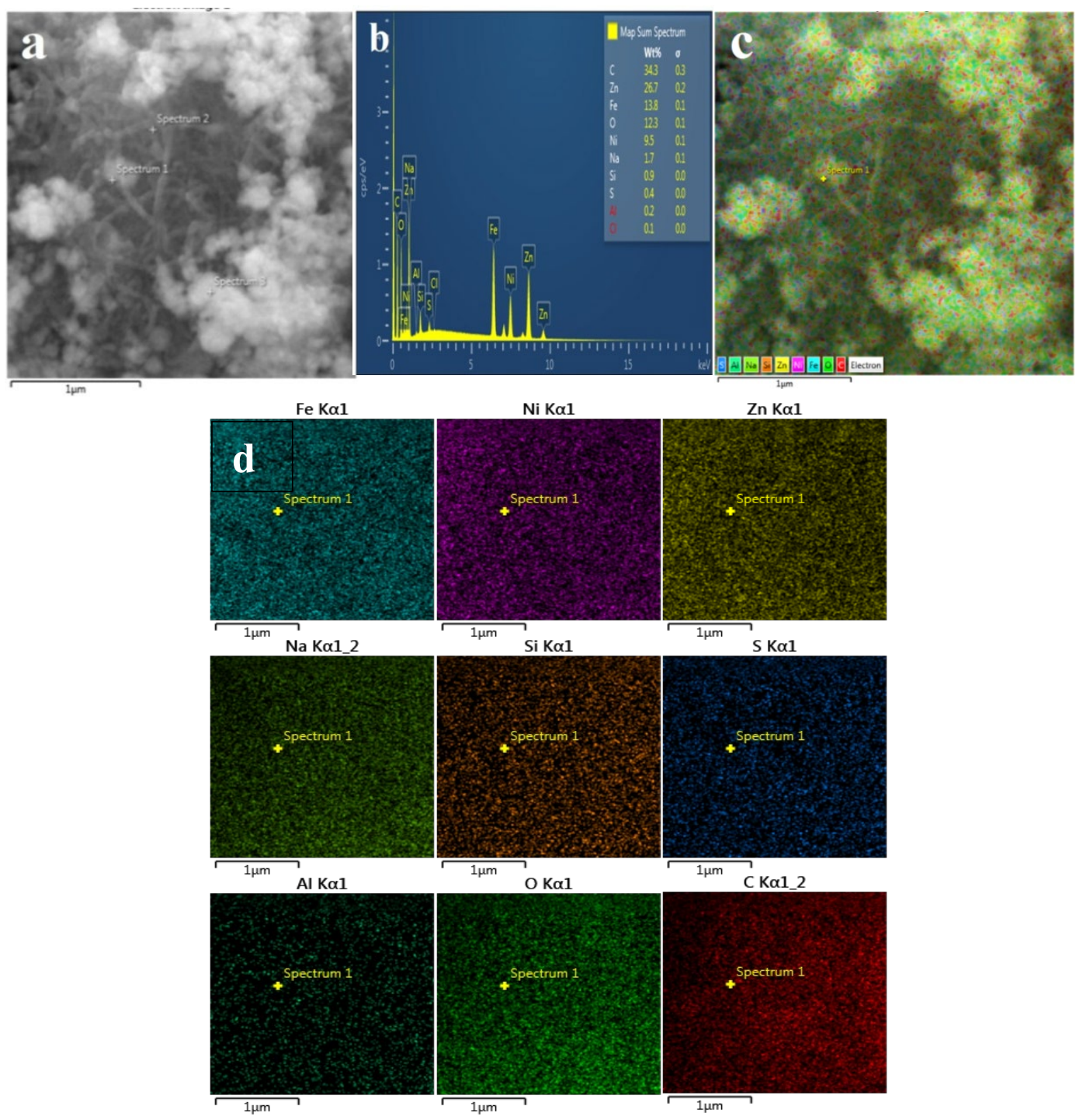

Fig. 6. (a) SEM image and (b) Energy-dispersive X-ray diffraction (EDX) spectrum and (c, d) Map of the elements distribution of $\mathrm{NiFe}_{2} \mathrm{O}_{4} / \mathrm{MWCNTs} / \mathrm{ZnO}$ hybrid nanocomposite.

\subsubsection{UV-Vis Diffuse Reflectance Spectroscopy (DRS) and Electrochemical Impedance Spectroscopy (EIS)}

The optical absorption technique can be employed for an examination of optically induced transitions and can give information about energy gap $\left(\mathrm{E}_{\mathrm{g}}\right)$ in crystalline materials, non-crystalline materials and the bond structure [59]. In the absorption process an electron transition from a lower to higher energy state happens via the absorption of a photon of specified energy. Hence, changes in the radiation absorbed can decide possible electron transitions. Fundamental absorption shows a surprising change in absorption and can be used in the determination of the optical band gap ( $\mathrm{E}_{\mathrm{g}}$ ) (see equation 4). 
Reflectance spectroscopy technique is closely related to the UV/Vis spectroscopy, in that both of them use visible light to excite valence electrons to empty orbitals. The difference is that in diffuse reflectance, we measures the relative change in the amount of light reflected off of a surface, whereas in $\mathrm{UV} / \mathrm{Vis}$ spectroscopy we measure the relative change of transmittance of light as it passes through a solution.

UV-Vis diffuse reflectance spectroscopy (DRS) was used to determine the optical absorption properties of the samples. Fig. 7(a) gives the UV-Vis DRS spectra of the $\mathrm{NiFe}_{2} \mathrm{O}_{4}$ and the $\mathrm{NiFe}_{2} \mathrm{O}_{4} / \mathrm{MWCNTs} / \mathrm{ZnO}$ composites. $\mathrm{ZnO}$ has a sharp optical-absorption edge at about $386 \mathrm{~nm}$, so it absorbs UV light to a degree higher than visible light. Fig. 7(a) showed that the $\mathrm{NiFe}_{2} \mathrm{O}_{4}$ absorbs the light in the whole region (200 to $800 \mathrm{~nm})$ due to its small band gap $(1.64 \mathrm{eV})$ which is consistent with the previous observations $[13,33]$. However, $\mathrm{NiFe}_{2} \mathrm{O}_{4}$ is rarely applied as a visible light photocatalyst alone since the electrons could not survive long in the conduction band and it will return to the valence band $\left(\mathrm{h}^{+}\right)$. Consequently photodegradation processes do not occurs as it should [60], but synergistic effect between $\mathrm{NiFe}_{2} \mathrm{O}_{4}, \mathrm{ZnO}$ and MWCNTs can leads to a significant enhancement in photo-activity due to the effective charge transfer from the $\mathrm{NiFe}_{2} \mathrm{O}_{4}$ to the $\mathrm{ZnO}$ and then to the MWCNTs and thus suppresses recombination of electron-hole pairs in the composite [33]. By extrapolating the linear portion near the commencement of absorption edge to x-axis, the optical band gap $\left(\mathrm{E}_{\mathrm{g}}\right)$ of $\mathrm{NiFe}_{2} \mathrm{O}_{4}$ and $\mathrm{NiFe}_{2} \mathrm{O}_{4} / \mathrm{MWCNTs} / \mathrm{ZnO}$ nanocomposites were found to be $1.64 \mathrm{eV}$ and $2.3 \mathrm{eV}$, respectively. The band gap of the hybrid nanocomposite was calculated as the average value obtained from the absorption spectrum (equation 4 and Fig. 7a) and the Tauc plot (equation 5 and Fig. 7c). The estimated band gaps are obtained from Fig. 7a by dividing 1240 by the intersection point of the extension line of the tangent of the curve $\left(\mathrm{NiFe}_{2} \mathrm{O}_{4}\right.$ and $\left.\mathrm{NiFe}_{2} \mathrm{O}_{4} / \mathrm{MWCNTs} / \mathrm{ZnO}\right)$ and the abscissa using the equation [24]:

$$
\begin{gathered}
E g=h c / \lambda_{g} \\
E g(e V)=1240 / \lambda_{g}
\end{gathered}
$$

where $h$ is Planck constant and $c$ is the speed of light. Results also were expressed from the plots $(\alpha h v)^{2}$ vs. photon energy (hv) as shown in Fig. 7(b, c) by Tauc equation [61-63]:

$$
(\alpha h v)^{2}=A\left(h v-E_{g}\right)
$$

where $\mathrm{A}$ is a constant that depends on the transition probability, and $\alpha$ is the absorption coefficient [64].

Compared to the known absorption curves of zinc oxide, the bias of the absorption spectra of the hybrid compound in the visible light area indicates that the combination of the $\mathrm{NiFe}_{2} \mathrm{O}_{4}$, the MWCNTs 
and the $\mathrm{ZnO}$ has enhanced the absorption efficiency of the light. This make the composite more effective and efficient in the photocatalytic processes to remove dyes contaminants under the sun's radiation.

In addition to the good light response ability of the light, good charge separation was supported by electrochemical impedance spectroscopy (EIS) to further characterize the transfer of the photogenerated electron-hole pairs. As showed in (Fig. 7d), the $\mathrm{NiFe}_{2} \mathrm{O}_{4} / \mathrm{MWCNTs} / \mathrm{ZnO}$ hybrid photocatalyst showed much smaller semicircle than the $\mathrm{NiFe}_{2} \mathrm{O}_{4}$ and the $\mathrm{NiFe}_{2} \mathrm{O}_{4} / \mathrm{MWCNTs}$, indicating that the $\mathrm{NiFe}_{2} \mathrm{O}_{4} / \mathrm{MWCNTs} / \mathrm{ZnO}$ photocatalyst exhibited the lowest charge-transfer resistance. Therefore, the existence of the $\mathrm{NiFe}_{2} \mathrm{O}_{4}$ and the $\mathrm{ZnO}$ in the surface layer of the MWCNTs could effectively separate the photogenerated electron and photogenerated holes produced by the $\mathrm{NiFe}_{2} \mathrm{O}_{4}$ and the $\mathrm{ZnO}$ and subsequently, hindering the recombination process [19].
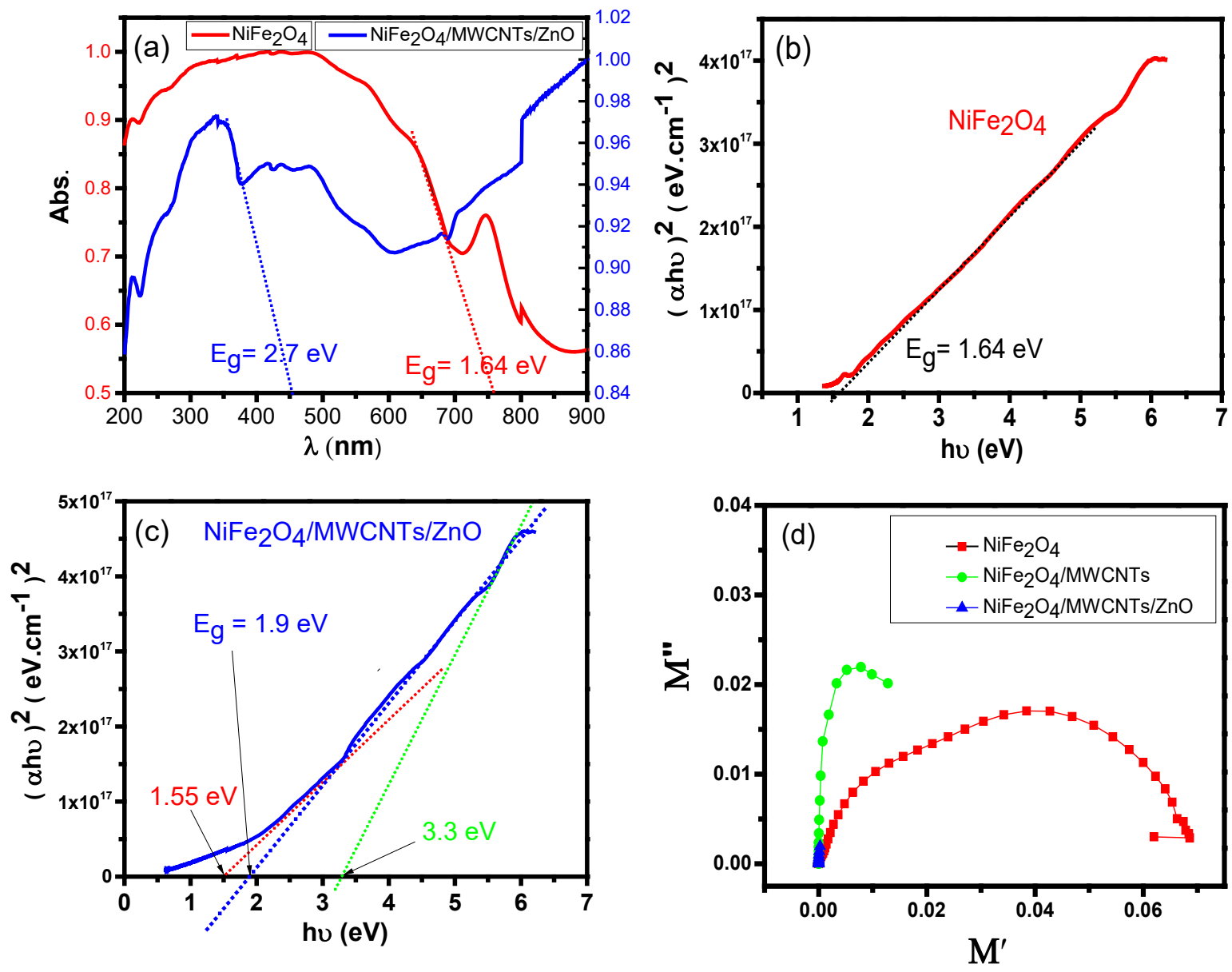

Fig. 7. (a) Absorption versus wavelength spectra of $\mathrm{NiFe}_{2} \mathrm{O}_{4}$ and $\mathrm{NiFe}_{2} \mathrm{O}_{4} / \mathrm{MWCNTs} / \mathrm{ZnO}$ composites. (b, c) Plot of $(\alpha \mathrm{hv})^{2}$ versus photon energy (hv) for $\mathrm{NiFe}_{2} \mathrm{O}_{4}$ and $\mathrm{NiFe}_{2} \mathrm{O}_{4} / \mathrm{MWCNTs} / \mathrm{ZnO}$ composites. (d) Electrochemical impedance spectroscopy (EIS) curves (Cole-Cole semicircles ( $M^{\prime \prime}$ vs. $\mathrm{M}^{\prime}$ )) of the $\mathrm{NiFe}_{2} \mathrm{O}_{4}$, the $\mathrm{NiFe}_{2} \mathrm{O}_{4} / \mathrm{MWCNTs}$ and the $\mathrm{NiFe}_{2} \mathrm{O}_{4} / \mathrm{MWCNTs} / \mathrm{ZnO}$ nanocomposites at room temperature. 


\subsubsection{Magnetic properties}

The magnetic properties of the $\mathrm{NiFe}_{2} \mathrm{O}_{4}$ and the $\mathrm{NiFe}_{2} \mathrm{O}_{4} / \mathrm{MWCNTs} / \mathrm{ZnO}$ samples were performed by VSM at room temperature with an applied magnetic field up to $20 \mathrm{KOe}$. The saturation magnetization $\left(\mathrm{M}_{\mathrm{s}}\right)$, remanence $\left(\mathrm{M}_{\mathrm{r}}\right)$ and coercivity $\left(\mathrm{H}_{\mathrm{c}}\right)$ of the samples are shown in Table I.

Table I. Magnetic parameters of $\mathrm{NiFe}_{2} \mathrm{O}_{4}$ and $\mathrm{NiFe}_{2} \mathrm{O}_{4} / \mathrm{MWCNTs} / \mathrm{ZnO}$ nanocomposites at room temperature.

\begin{tabular}{|c|c|c|c|}
\hline Sample & Magnetization $\left(\mathrm{M}_{\mathrm{s}}\right)(\mathrm{emu} / \mathrm{g})$ & Coercivity $\left(\mathrm{H}_{\mathrm{c}}\right)(\mathrm{Oe})$ & Remanence $\left(\mathrm{M}_{\mathrm{r}}\right)(\mathrm{emu} / \mathrm{g})$ \\
\hline $\mathrm{NiFe}_{2} \mathrm{O}_{4}$ & 37.77 & 157.67 & 6.42 \\
\hline $\mathrm{NiFe}_{2} \mathrm{O}_{4} / \mathrm{MWCNTs} / \mathrm{ZnO}$ & 17.02 & 159.45 & 3.28 \\
\hline
\end{tabular}

The hysteresis loops shown in Fig. 8 revealed that the $\mathrm{NiFe}_{2} \mathrm{O}_{4}$ and the $\mathrm{NiFe}_{2} \mathrm{O}_{4} / \mathrm{MWCNTs} / \mathrm{ZnO}$ nanocomposites have a superparamagnetic behavior at room temperature. The saturation magnetization $\left(\mathrm{M}_{\mathrm{s}}\right)$ value of the $\mathrm{NiFe}_{2} \mathrm{O}_{4} / \mathrm{MWCNTs} / \mathrm{ZnO}$ hybrid $\left(17.021 \mathrm{emu} \mathrm{g}^{-1}\right)$ is much lower than that of the pure $\mathrm{NiFe}_{2} \mathrm{O}_{4}\left(37.8 \mathrm{emu} \mathrm{g}{ }^{-1}\right)$, which is ascribed to the existence of other nonmagnetic material, i.e. the MWCNTs and the $\mathrm{ZnO}[24,38,41]$. Also, as we found before in the structural properties, the size of the NPs of nickel ferrite formed on the surface of the MWCNTs is smaller than that of the $\mathrm{NiFe}_{2} \mathrm{O}_{4}$ bare material. So, in this case, the spins on the surface of the NPs are canted and hence the magnetization is reduced $[65,66]$.

Mainly, the magnetic order in a spinel ferrites material such as $\mathrm{NiFe}_{2} \mathrm{O}_{4}$ is due to the super exchange interaction mechanism happening between the metal ions in the tetrahedral and the octahedral sublattices. The spinel can be of normal or inverse structure according to the distribution of the cations on the interstitial tetrahedral (A) and octahedral (B) sites [67]. In the normal structure all divalent $\mathrm{A}^{2+}$ (trivalent $\mathrm{B}^{3+}$ ) cations occupy tetrahedral (octahedral) lattice sites exclusively, while in the inverse, the trivalent $\mathrm{B}^{3+}$ cations distributed equally across the tetrahedral (A) and octahedral (B) sites and the divalent $\mathrm{A}^{2+}$ cations only occupy the $\mathrm{B}$ sites. A mixture of both structures is quantified by the inversion parameter $\lambda$. Here, $\lambda$ is the fraction of $\mathrm{A}^{2+}$-cations occupying $\mathrm{B}$ sites. $\lambda=0$ denotes a normal $\left(\mathrm{A}^{2+}\left[\mathrm{B}^{3+}\right.\right.$ $\left.\left.\mathrm{B}^{3+}\right] \mathrm{O}_{4}\right)$ and $\lambda=1$ denotes a fully inverse spinel lattice $\left(\mathrm{B}^{3+}\left[\mathrm{A}^{2+} \mathrm{B}^{3+}\right] \mathrm{O}_{4}\right)[67-70]$.

The net magnetization in the inverse spinel $\mathrm{NiFe}_{2} \mathrm{O}_{4}$ is the result of these two sub-lattices in which the $\mathrm{Ni}^{2+}$ ions incline to occupy the B-site, and $\mathrm{Fe}^{3+}$ ions occupy both $\mathrm{A}$ - and B-sites [71, 72] as the chemical composition formula $\left[\mathrm{Fe}^{3+}\right]\left[\mathrm{Ni}^{2+} \mathrm{Fe}^{3+}\right] \mathrm{O}_{4}[72]$. In the bulk inverse spinel $\mathrm{NiFe}_{2} \mathrm{O}_{4}$, the distribution of the $\mathrm{Fe}^{3+}$ ions of high magnetic moment $\left(5 \mu_{\mathrm{B}}\right)$ is equal on both the $\mathrm{A}$ - and the B-sites [68]. The magnetic moments of the $\mathrm{Fe}^{3+}$ cations is equivalent to the antiferromagnetic conjugation between the A- and B sites, only the $\mathrm{Ni}^{2+}$ cations is taken into account for the net magnetization of $2 \mu_{\mathrm{B}} / \mathrm{f} . \mathrm{u}$ [68]. 
The magnetic behavior of the NPs is determined by the structural, the magnetic and the surface properties of the individual NPs and the interactions among them. Practically, inter-particle interactions are inevitable mainly due to van der Waals forces and the interaction of magnetic dipolar of magnetic moments. By reducing the inter-particle distances in magnetic NPs, superparamagnetic relaxation, for instance, is affected remarkably [73, 74]. The mechanism can be explained in terms of spin-glass like state, spin canting and spin-disorder in the surface layers of NPs because of the broken exchange interaction, local chemical disorder and an unlike local symmetry for the surface atoms [71]. On the surface of the ferrite NPs, the spins can be in a disturbed state because of several reasons: (a) Differences in coordination of the surface cations can lead to a distribution of the net exchange fields, whether positive or negative with respect to a cations sub-lattice; (b) because an oxygen ion mediated the super exchange interaction, and if an oxygen ion is missing, the exchange bonds will be broken [75]. In magnetic NPs, the most studied finite-size effects are the superparamagnetic limit and the single domain limit [76]. The reduction of the grain size can strongly affects the magnetic properties of the materials because of the influence of the thermal energy over the ordering of the magnetic moment causing a paramagnetic relaxation phenomenon [74]. Depending on the magnetic domain theory, there is a critical size $d_{s}$ of single domain particles. If the particle size $D$ is larger than $d_{s}$, the magnetic particles are multi-domain particles and their coercivity $\left(\mathrm{H}_{\mathrm{c}}\right)$ increases with the decrease of D. With reduced particle size to a critical diameter, the value of coercivity increases to a maximum value. When the particle size decreases furthermore below the critical size, the coercivity decreases toward zero and the particles become superparamagnetic [33, 77]. This may explain why the coercivity of the hybrid nanocomposites is slightly larger than that of the unsupported ferrite [33] as in Table I. Also, as in the table, the remanence $\left(\mathrm{M}_{\mathrm{r}}\right)$ of both compounds is very small and almost equal to zero. The impermanent magnetization $\left(\mathrm{M}_{\mathrm{r}}=0\right)$ after the magnetic field removal in superparamagnetic materials is an important feature for carriers in magnetic target [78].

Although the $\mathrm{M}_{\mathrm{s}}$ value of the hybrid nanocomposite is much lower than that of the $\mathrm{NiFe}_{2} \mathrm{O}_{4}$, it is still relatively high and ensures high magnetic response toward an external magnetic field. The $\mathrm{NiFe}_{2} \mathrm{O}_{4} / \mathrm{MWCNTs} / \mathrm{ZnO}$ hybrid composite showed strong attraction with a magnet, which is important for their applications in the biological field to eliminate organic pollutants and in for an economical approach for the treatment of industrial wastewater, as the nanocomposite can be reused. 


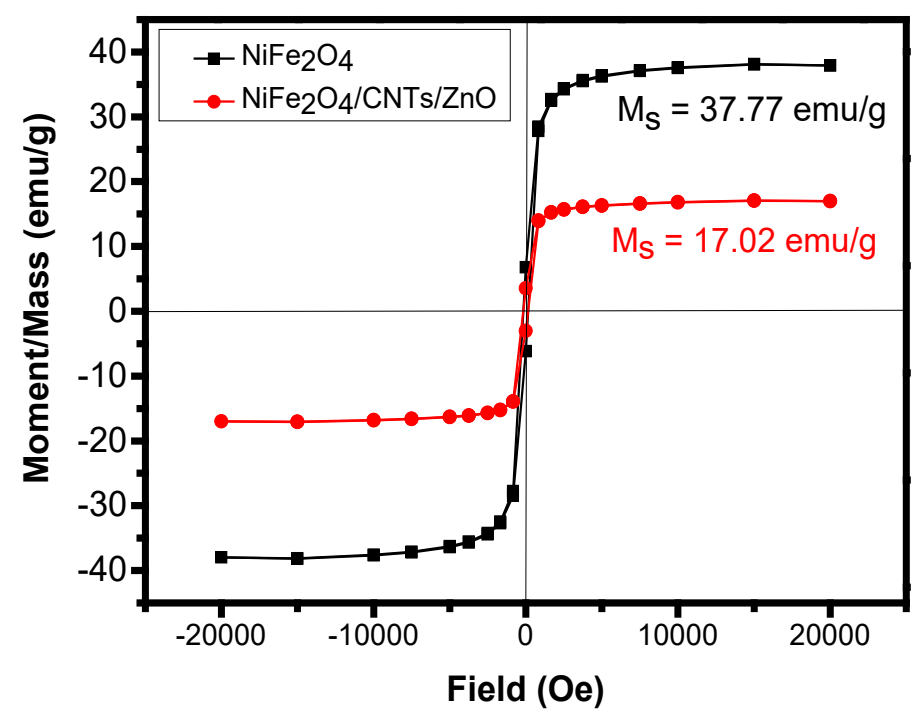

Fig. 8. Magnetic hysteresis loops of $\mathrm{NiFe}_{2} \mathrm{O}_{4}$ and $\mathrm{NiFe}_{2} \mathrm{O}_{4} / \mathrm{MWCNTs} / \mathrm{ZnO}$ nanocomposites at room temperature.

\subsection{Photocatalytic activity of the $\mathrm{NiFe}_{2} \mathrm{O}_{4} / \mathrm{MWCNTs} / \mathrm{ZnO}$ hybrid photocatalyst}

The photocatalytic activity for decolorization of Methylene Blue (MB) dye (molecular formula: $\mathrm{C}_{16} \mathrm{H}_{18} \mathrm{ClN}_{3} \mathrm{~S}_{3} 3 \mathrm{H}_{2} \mathrm{O}$ ) as an example of the sun radiation driven photocatalytic activity using $\mathrm{NiFe}_{2} \mathrm{O}_{4} / \mathrm{MWCNTs} / \mathrm{ZnO}$ hybrid nanocomposite catalyst compared with the adsorption process has been investigated (Fig. 9a). In addition, the photodegradation activity is compared with the performance of $\mathrm{NiFe}_{2} \mathrm{O}_{4}$ and $\mathrm{ZnO}$ under solar light irradiation for 300 minutes. Then, to describe the corresponding experimental data and to evaluate the mechanism of photocatalytic process, the pseudo-first-order kinetic model was applied to fit the data (see the correlation factors $\left(R^{2}\right)$ of the catalysts in Fig. $9 b$ ).

With normal $\mathrm{pH}$, the decolorization efficiency of the MB solution for 300 minutes under solar light irradiation using $\mathrm{NiFe}_{2} \mathrm{O}_{4} / \mathrm{MWCNTs} / \mathrm{ZnO}, \mathrm{NiFe}_{2} \mathrm{O}_{4}$ and $\mathrm{ZnO}$ catalysts were $73.02 \%, 11.48 \%$ and $43.78 \%$, respectively, and the corresponding decolorization rate constants $\left(\mathrm{k}_{\text {app }}\right)$ were $0.00438 \mathrm{~min}^{-1}$, $4.12857 \mathrm{E}^{-4} \mathrm{~min}^{-1}$ and $0.002 \mathrm{~min}^{-1}$, respectively, according to the pseudo first-order kinetic model (equation 2). The $\mathrm{NiFe}_{2} \mathrm{O}_{4} / \mathrm{MWCNTs} / \mathrm{ZnO}$ hybrid showed a photocatalytic efficiency ( $\eta$ ) of $73.02 \%$ at a $\mathrm{pH}=6.66(\mathrm{pH}$ of the dye solution) and $98 \%$ with $\mathrm{pH}=11.55$ at the same conditions (the same irradiation time and the same concentration of the catalyst) (Fig. 10). 

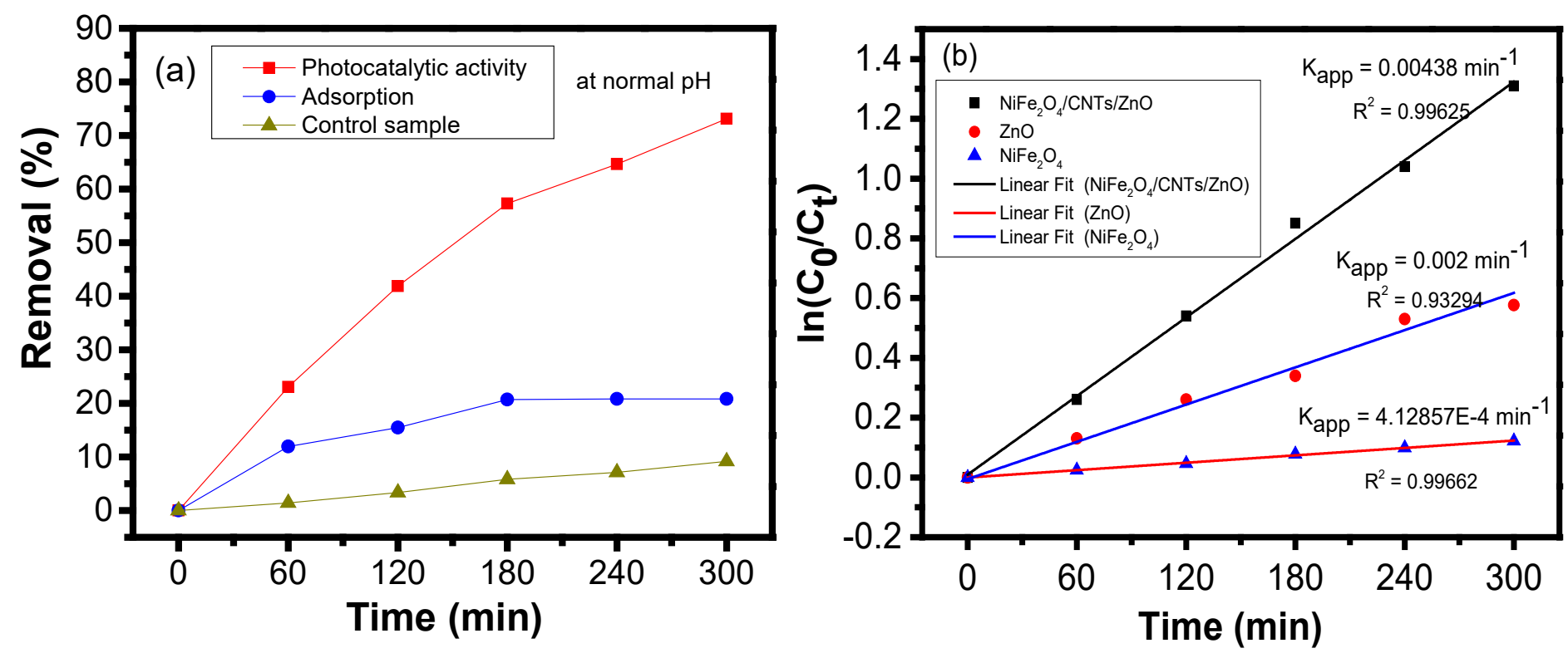

Fig. 9. (a) Adsorption and photocatalytic efficiency of $\mathrm{MB}$ dye degradation using $\mathrm{NiFe}_{2} \mathrm{O}_{4} / \mathrm{MWCNTs} / \mathrm{ZnO}$ photocatalyst for 300 min. (b) $\ln \left(\mathrm{C}_{0} / \mathrm{C}_{\mathrm{t}}\right)$ versus irradiation time for MB degradation using $\mathrm{NiFe}_{2} \mathrm{O}_{4} / \mathrm{MWCNTs} / \mathrm{ZnO}, \mathrm{ZnO}$, and $\mathrm{NiFe}_{2} \mathrm{O}_{4}$ nanocatalysts, where pseudo-first-order kinetic model was applied to describe corresponding experimental data. (Normal pH, catalyst concentration: $1.0 \mathrm{~g} / \mathrm{L}$, concentration of MB dye solution: $20 \mathrm{mg} / \mathrm{L}$ ).
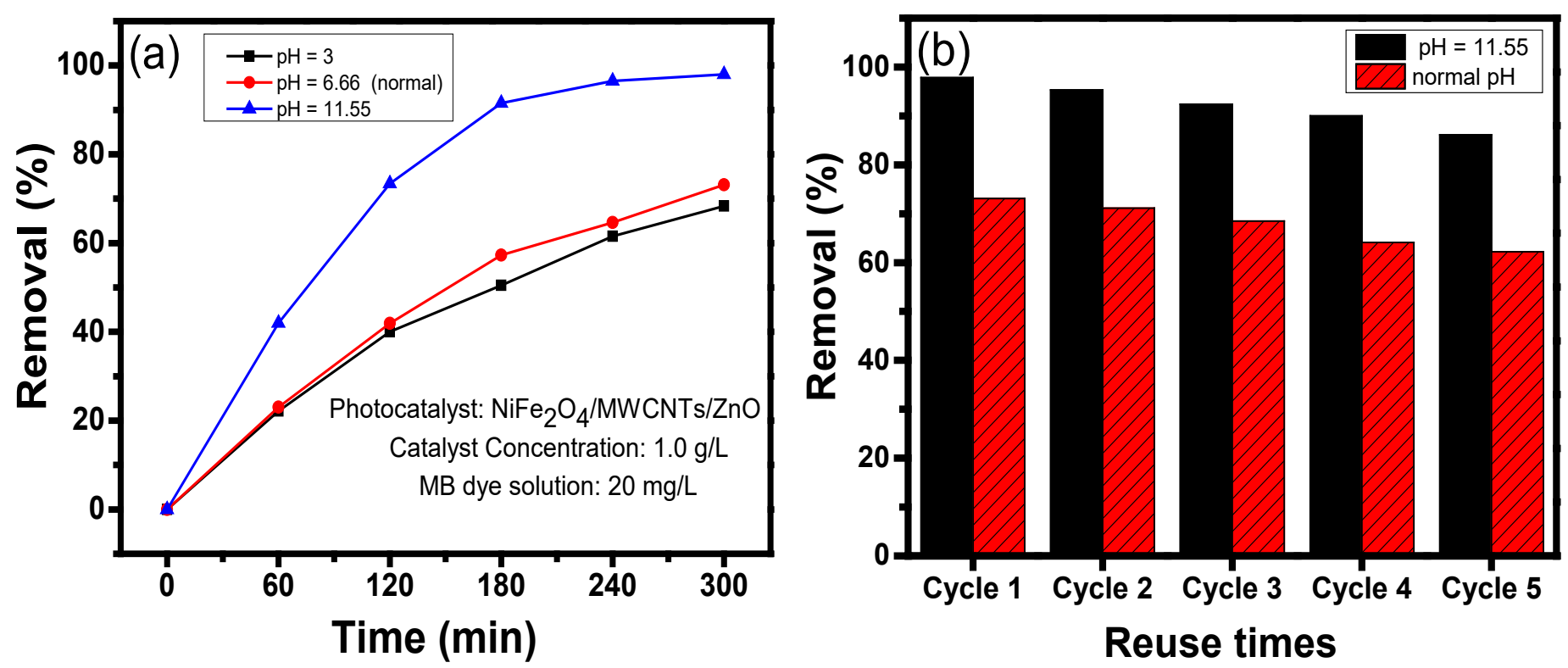

Fig. 10. (a) Photocatalytic efficiency of $M B$ dye degradation as a function of solar light irradiation time using $\mathrm{NiFe}_{2} \mathrm{O}_{4} / \mathrm{MWCNTs} / \mathrm{ZnO}$ nanocomposite for $300 \mathrm{~min}$ with different $\mathrm{pH}$ values (3, 6.66 (normal) and 11.55). (b) Catalyst reuse for five cycles under the same conditions at $\mathrm{pH}=6.7$ (normal) and $\mathrm{pH}=11.6$. 
Obviously, from Fig. $9 \mathrm{~b}$, in the presence of the $\mathrm{NiFe}_{2} \mathrm{O}_{4}$, there is no significant increase of the $\mathrm{MB}$ degradation, and $\mathrm{ZnO}$ has more excellent photocatalytic efficiency compared to $\mathrm{NiFe}_{2} \mathrm{O}_{4}$.

The reaction mechanism for the $\mathrm{MB}$ dye photo-degradation using the $\mathrm{ZnO}$, the $\mathrm{NiFe}_{2} \mathrm{O}_{4}$ and the $\mathrm{NiFe}_{2} \mathrm{O}_{4} / \mathrm{MWCNTs} / \mathrm{ZnO}$ photocatalysts is similar. The first step (before starting the exposure to the irradiation) begins by adsorbing the dye on the catalyst surface through stirring, which is an essential step before the photocatalytic interaction [13, 33, 38, 79] (Fig. 11). The good removal efficiency for the MB dye by the $\mathrm{NiFe}_{2} \mathrm{O}_{4} / \mathrm{MWCNTs} / \mathrm{ZnO}$ corresponds to UV-Vis DRS results which showed a high absorption of the irradiation in the visible and ultraviolet regions. Fig. 11 illustrates the photocatalytic decolorization of the $\mathrm{MB}$ dye using the $\mathrm{NiFe}_{2} \mathrm{O}_{4} / \mathrm{MWCNTs} / \mathrm{ZnO}$ photocatalyst under solar light irradiation and illustrates the magnetic separation. In order to compare the performance of the $\mathrm{NiFe}_{2} \mathrm{O}_{4} / \mathrm{MWCNTs} / \mathrm{ZnO}$ photocatalyst to the other similar photocatalysts, the photocatalytic activity of other related magnetic carbon nanotubes (Mag-CNTs) and related $\mathrm{ZnO} /$ carbon nanotubes nanocomposites are shown in Table II.

Table II. Photocatalytic activity of related mediated composites.

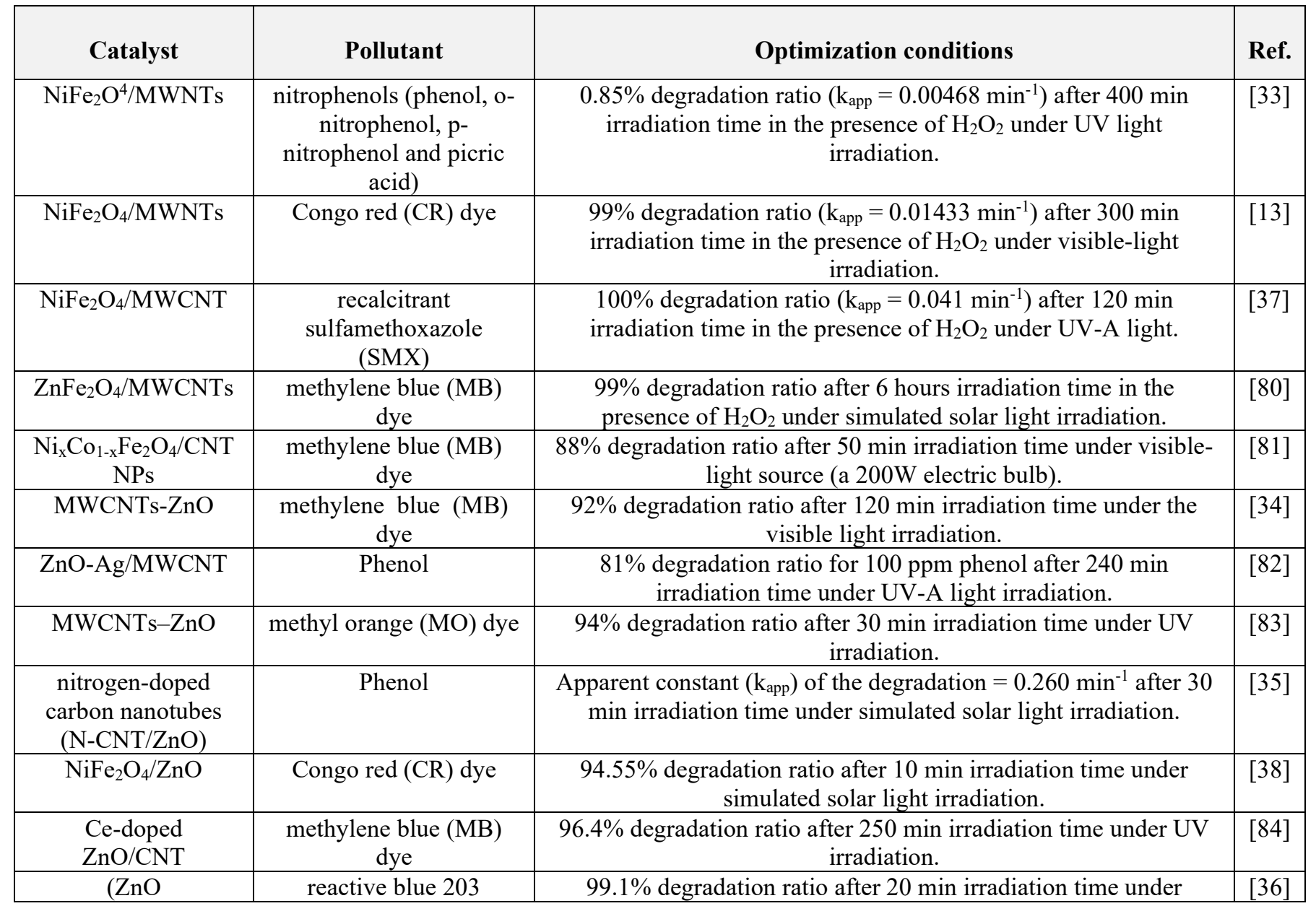




\begin{tabular}{|c|c|c|c|}
\hline (NPs)/MWCNTs & (RB203) dye & UV radiation intensity of 23 mW/ $\mathrm{cm}^{2}$. & \\
\hline $\mathrm{ZnO} / \mathrm{MWCNT}$ & $\begin{array}{c}\text { methylene blue (MB) } \\
\text { dye }\end{array}$ & $\begin{array}{c}\text { 93\% degradation ratio after 40 min irradiation time under UV light } \\
\text { irradiation (125 W mercury lamp). }\end{array}$ & {$[85]$} \\
\hline
\end{tabular}

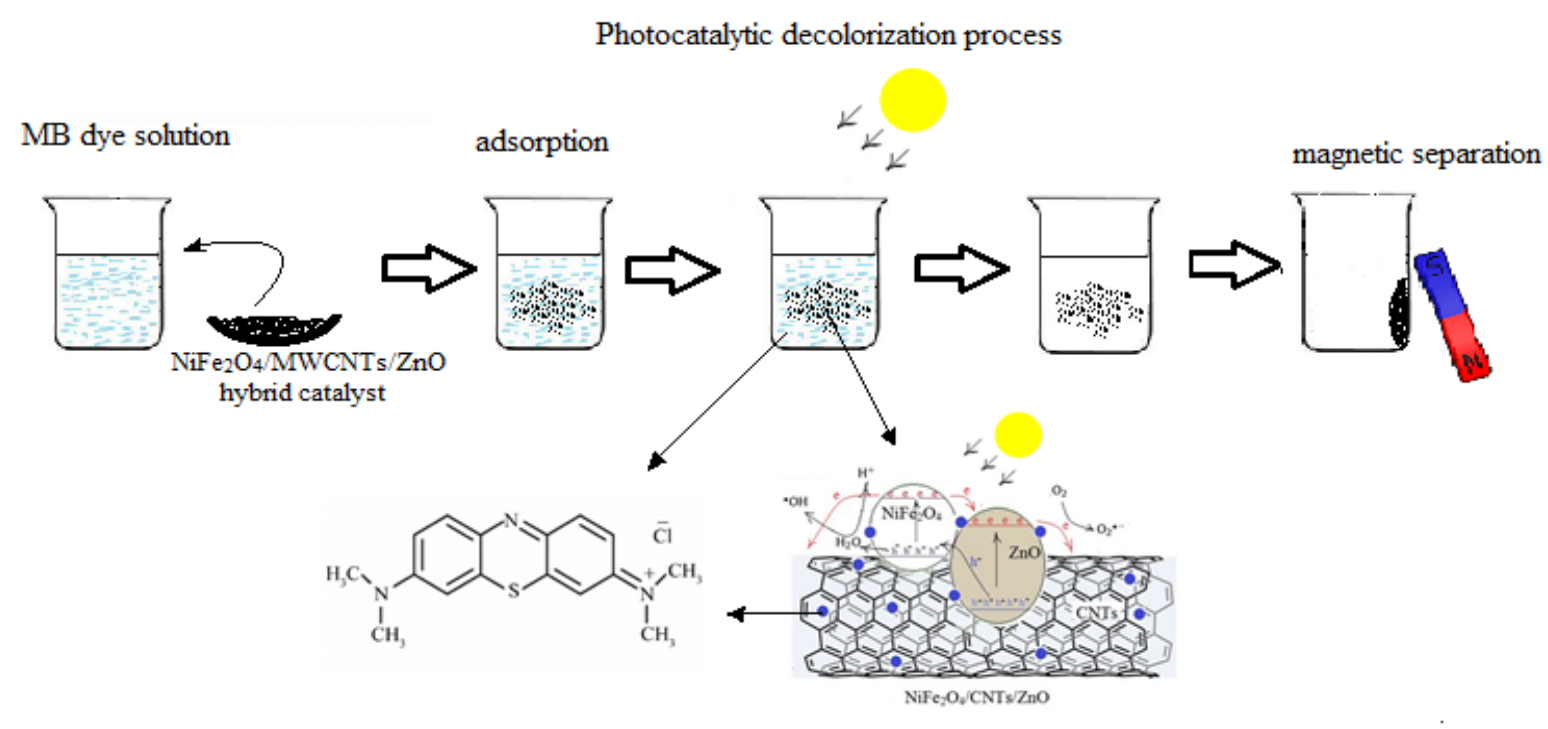

Fig. 11. Diagram illustrates the photocatalytic decolorization of $\mathrm{MB}$ dye using $\mathrm{NiFe}_{2} \mathrm{O}_{4} / \mathrm{MWCNTs} / \mathrm{ZnO}$ hybrid catalyst under solar light irradiation and illustrates the magnetic separation.

\subsubsection{Reproducibility}

Recycling can effectively reduce the waste of resources and environmental pollution $[16,86]$. The reproducibility of the $\mathrm{NiFe}_{2} \mathrm{O}_{4} / \mathrm{MWCNTs} / \mathrm{ZnO}$ photocatalyst for 5 cycles was displayed in Fig. $10 \mathrm{~b}$. It could be clearly seen that the photocatalyst could be used at least 5 cycles with a little loss of photocatalytic efficiency, indicating that it had good photochemical stability. The loss of photocatalytic efficiency after five cycles for $\mathrm{MB}$ dye degradation might be ascribed to the sample loss during the magnetic separation and recovery process.

\subsubsection{Mechanism of photocatalytic decolorization process}

Based on the experimental results and some previously submitted reports [2, 38] on the mechanism of the photocatalytic decolorization to remove organic pollutants, the presented mechanism can be described as follows: at first, the MB dye molecules are adsorbed on the outer surfaces of the NPs on the catalyst. By exposure to solar radiation, electrons $\left(\mathrm{e}^{-}\right)$in the valence band (VB) of $\mathrm{NiFe}_{2} \mathrm{O}_{4}$ and $\mathrm{ZnO}$ are excited to the conduction band (CB). This will simultaneously lead to generate gaps with positive charge in the VB. Due to the difference in energy bands between the nickel ferrite, the carbon 
nanotubes and the $\mathrm{ZnO}$, the photo-generated electrons $\left(\mathrm{e}^{-}\right)$can be transferred to the $\mathrm{ZnO}$ and to the MWCNTs instantly. This causes charge separation and stabilization, subsequently hindering the recombination process $[40,41]$. After that, the generated electrons react with $\mathrm{O}_{2}$ contained in the solution to yield $\mathrm{O}^{2-}$ ions which will further react with $\mathrm{H}_{2} \mathrm{O}$ forming ${ }^{\circ} \mathrm{OH}$ hydroxyl radical [24]. It is established that the photocatalytic reactive species are capable of attacking and degrading organic pollutants in the photocatalytic reaction [87-89].

The VB potential of the $\mathrm{ZnO}$ is more positive than that of the $\mathrm{NiFe}_{2} \mathrm{O}_{4}$ while the $\mathrm{CB}$ potential of $\mathrm{NiFe}_{2} \mathrm{O}_{4}$ is more negative than that of the $\mathrm{ZnO}$. Therefore, the photo-produced electrons $\left(\mathrm{e}^{-}\right)$in the $\mathrm{NiFe}_{2} \mathrm{O}_{4}$ will be transferred across the interface of the $\mathrm{NiFe}_{2} \mathrm{O}_{4} / \mathrm{ZnO}$ hybrid to the surface of $\mathrm{ZnO}$ [38] then to the MWCNTs. The active species included in the photocatalytic degradation reaction are photogenerated holes $\left(\mathrm{h}^{+}\right)$, hydroxyl radicals $\left({ }^{\circ} \mathrm{OH}\right)$ and superoxide radical anions $\left(\mathrm{O}_{2}{ }^{--}\right)$. The surface-adsorbed MB molecules were attacked by the active species (free radicals) to become simple compounds such as $\mathrm{CO}_{2}, \mathrm{H}_{2} \mathrm{O}$ and other byproducts.

For both zinc oxide and nickel ferrite in particular this low efficiency in the photocatalytic degradation is due to the recombination process of the photo-induced electron-hole pairs that happen immediately and does not allow the pairs to flow and interact with the dye solution. The high photocatalytic efficiency at the high values of the $\mathrm{pH}$ is due to the increase of the amount of hydroxide anions $\left(\mathrm{OH}^{-}\right)$in the solution which contribute to the decolorization process and this is the same effect of other oxidizing agents such as hydrogen peroxide $\left(\mathrm{H}_{2} \mathrm{O}_{2}\right)$.

According to the our control sample and as in shown in previous studies on other dyes [24], it is worth mentioning that the solar radiation alone contributes in the breakdown of the bonds in methylene blue dye with degradation efficiency up to $10 \%$ at the end of the irradiation time. This is due to the direct effect of photons of solar radiation. Just as photons directly generate electron-gap pairs by photocatalysis and then free radicals are created, photons directly break the bonds of the dye and also indirectly affect in increasing the kinetic energy of free radicals formed. 


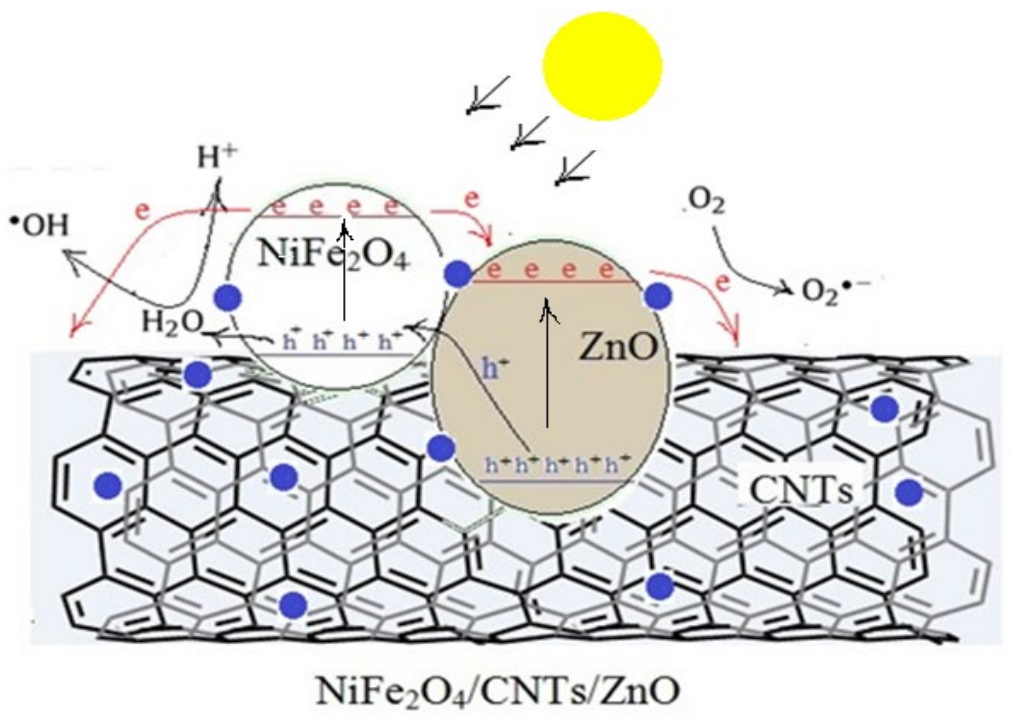

Fig. 12. Diagram of the proposed mechanism of $\mathrm{MB}$ dye removal by photocatalytic decolorization over $\mathrm{NiFe}_{2} \mathrm{O}_{4} / \mathrm{MWCNTs} / \mathrm{ZnO}$ hybrid catalyst.

Based on these results, the most likely mechanism of the photocatalytic degradation is illustrated in Fig. 12 and equations $6-9$. The main process is as the following:

$$
\begin{aligned}
& \mathrm{NiFe}_{2} \mathrm{O}_{4} / \mathrm{MWCNTs} / \mathrm{ZnO}+h v \rightarrow \mathrm{NiFe}_{2} \mathrm{O}_{4} / \mathrm{MWCNTs} / \mathrm{ZnO}\left(\mathrm{e}_{(\mathrm{CB})}^{-}+\mathrm{h}^{+}(\mathrm{VB})\right. \\
& \mathrm{O}_{2}+\mathrm{e}^{-} \rightarrow \mathrm{O}_{2}^{--} \\
& \mathrm{H}_{2} \mathrm{O}+\mathrm{h}^{+} \rightarrow \mathrm{H}^{+}+{ }^{\cdot} \mathrm{OH} \\
& \mathrm{MB}-\mathrm{NiFe}_{2} \mathrm{O}_{4} / \mathrm{MWCNTs} / \mathrm{ZnO}+\mathrm{O}_{2}^{--} / \mathrm{h}^{+} /{ }^{\circ} \mathrm{OH} \rightarrow \mathrm{NiFe}_{2} \mathrm{O}_{4} / \mathrm{MWCNTs} / \mathrm{ZnO}+\mathrm{H}_{2} \mathrm{O}+\mathrm{CO}_{2}+\text { other } \\
& \text { byproducts }
\end{aligned}
$$

Based on the structural, optical and magnetic properties of the $\mathrm{NiFe}_{2} \mathrm{O}_{4} / \mathrm{MWCNTs} / \mathrm{ZnO}$ photocatalyst, it is shown that the nanocomposite possesses good performance in the removal of the dyes from solutions through the processes of absorption and photocatalysis under solar radiation. Taking into account the need to prolong the time required to oxidize the carbon nanotubes; we can avoid those defects related to morphology and ensure a homogeneous decorating process on the entire surface of the carbon nanotubes, thus increasing the photocatalytic efficiency.

As a result, the $\mathrm{NiFe}_{2} \mathrm{O}_{4} / \mathrm{MWCNTs} / \mathrm{ZnO}$ is a novel multifunctional photocatalyst for an economic treatment of dyed wastewater with the advantages of low cost, good adsorption, high photocatalytic activity with magnetically separation possibility. 


\section{Conclusions}

Novel multifunctional $\mathrm{NiFe}_{2} \mathrm{O}_{4} / \mathrm{MWCNTs} / \mathrm{ZnO}$ hybrid nanocomposite was synthesized by the hydrothermal and the co-precipitation methods and used as an efficient photocatalyst with good adsorption and photocatalytic activity. The $\mathrm{NiFe}_{2} \mathrm{O}_{4} / \mathrm{MWCNTs} / \mathrm{ZnO}$ hybrid composite exhibited enhanced photocatalytic activity compared to the $\mathrm{NiFe}_{2} \mathrm{O}_{4}$ and to the $\mathrm{ZnO}$ for the decolorization of $\mathrm{MB}$ as a model pollutant under solar light irradiation for 5 hours. High removal efficiency was obtained at relatively high values of the $\mathrm{pH}$, when the catalyst concentration was $1.0 \mathrm{~g} / \mathrm{L}$ and the concentration of MB dye solution was $20 \mathrm{mg} / \mathrm{L}$. Pseudo-first-order kinetic model was applied to demonstrate the corresponding experimental data. It was found that the combination of the $\mathrm{NiFe}_{2} \mathrm{O}_{4}$, the $\mathrm{MWCNTs}$ and the $\mathrm{ZnO}$ enhances the absorption efficiency of light with band gap of $2.3 \mathrm{eV}$ for the $\mathrm{NiFe}_{2} \mathrm{O}_{4} / \mathrm{MWCNTs} / \mathrm{ZnO}$ hybrid catalyst. In the photocatalytic degradation reaction, the ${ }^{\circ} \mathrm{OH}, \mathrm{h}^{+}, \mathrm{O}_{2}{ }^{--}$ free radicals attack the surface-adsorbed MB molecules and turn them to simple compounds such as $\mathrm{CO}_{2}, \mathrm{H}_{2} \mathrm{O}$ and other products. It was shown that the $\mathrm{NiFe}_{2} \mathrm{O}_{4} / \mathrm{MWCNTs} / \mathrm{ZnO}$ hybrid nanocomposite is a super paramagnetic at room temperature with saturation magnetization $\left(\mathrm{M}_{\mathrm{s}}\right)$ of $17.02 \mathrm{emu} / \mathrm{g}$. The hybrid composite is of potential in the biological applications field specifically to remove organic pollutants and in economic treatment of the industrial wastewater. The decolorization efficiency of the MB solution for a duration of 300 minutes using the $\mathrm{NiFe}_{2} \mathrm{O}_{4} / \mathrm{MWCNTs} / \mathrm{ZnO}$, the $\mathrm{NiFe}_{2} \mathrm{O}_{4}$ and the $\mathrm{ZnO}$ catalysts were $73.02 \%, 11.48 \%$ and $43.78 \%$, respectively, with corresponding apparent rate constant ( $\mathrm{k}_{\mathrm{app}}$ ) of $0.00438 \mathrm{~min}^{-1}, 4.12857 \mathrm{E}^{-4} \mathrm{~min}^{-1}$ and $0.002 \mathrm{~min}^{-1}$, respectively.

\section{Acknowledgements}

The authors wish to thank the Azal Pharmaceutical industries "Azal Pharmaceuticals Company Ltd. Sudan", Al Khartoum Bahri, Khartoum, Sudan for supporting of this work.

\section{References}

[1] P. Zhang, B.Y. Guan, L. Yu, X.W.D. Lou, Facile synthesis of multi-shelled ZnS-CdS cages with enhanced photoelectrochemical performance for solar energy conversion, Chem, 4 (2018) 162-173.

[2] Z. Lu, G. Zhou, M. Song, X. Liu, H. Tang, H. Dong, P. Huo, F. Yan, P. Du, G. Xing, Development of magnetic imprinted PEDOT/CdS heterojunction photocatalytic nanoreactors: 3-Dimensional specific recognition for selectively photocatalyzing danofloxacin mesylate, Applied Catalysis B: Environmental, 2019, doi: 10.1016/j.apcatb.2019.118433.

[3] J. Byun, W. Huang, D. Wang, R. Li, K.A. Zhang, $\mathrm{CO}_{2}$-Triggered Switchable Hydrophilicity of a Heterogeneous Conjugated Polymer Photocatalyst for Enhanced Catalytic Activity in Water, Angewandte Chemie International Edition, 57 (2018) 2967-2971. 
[4] Z. Lin, C. Du, B. Yan, C. Wang, G. Yang, Two-dimensional amorphous NiO as a plasmonic photocatalyst for solar $\mathrm{H}_{2}$ evolution, Nature communications, 9 (2018) 4036.

[5] T. Su, Q. Shao, Z. Qin, Z. Guo, Z. Wu, Role of interfaces in two-dimensional photocatalyst for water splitting, Acs Catalysis, 8 (2018) 2253-2276.

[6] Z. Lu, F. He, C.Y. Hsieh, X. Wu, M. Song, X. Liu, Y. Liu, S. Yuan, H. Dong, S. Han, Magnetic Hierarchical Photocatalytic Nanoreactors: Toward Highly Selective $\mathrm{Cd}^{2+}$ Removal with Secondary Pollution Free Tetracycline Degradation, ACS Applied Nano Materials, 2 (2019) 1664-1674.

[7] K. Chattopadhyay, S. Maiti, S. Pal, Recent advances in low temperature, solution processed morphology tailored $\mathrm{ZnO}$ nano-architecture for electron emission and photocatalysis applications, CrystEngComm, 17 (2015) 9264-9295.

[8] H. Zhu, R. Jiang, L. Xiao, Y. Chang, Y. Guan, X. Li, G. Zeng, Photocatalytic decolorization and degradation of Congo Red on innovative crosslinked chitosan/nano-CdS composite catalyst under visible light irradiation, Journal of Hazardous Materials, 169 (2009) 933-940.

[9] J. Xu, Z. Cao, Y. Zhang, Z. Yuan, Z. Lou, X. Xu, X. Wang, A review of functionalized carbon nanotubes and graphene for heavy metal adsorption from water: Preparation, application, and mechanism, Chemosphere, 195 (2018) 351-364.

[10] T. Mühl, D. Elefant, A. Graff, R. Kozhuharova, A. Leonhardt, I. Mönch, M. Ritschel, P. Simon, S. Groudeva-Zotova, C. Schneider, Magnetic properties of aligned Fe-filled carbon nanotubes, Journal of applied physics, 93 (2003) 7894-7896.

[11] V.D. Punetha, S. Rana, H.J. Yoo, A. Chaurasia, J.T. McLeskey Jr, M.S. Ramasamy, N.G. Sahoo, J.W. Cho, Functionalization of carbon nanomaterials for advanced polymer nanocomposites: A comparison study between CNT and graphene, Progress in Polymer Science, 67 (2017) 1-47.

[12] M. Bahgat, A.A. Farghali, W. El Rouby, M. Khedr, M.Y. Mohassab-Ahmed, Adsorption of methyl green dye onto multi-walled carbon nanotubes decorated with Ni nanoferrite, Applied Nanoscience, 3 (2013) 251-261.

[13] H.-Y. Zhu, R. Jiang, S.-H. Huang, J. Yao, F.-Q. Fu, J.-B. Li, Novel magnetic $\mathrm{NiFe}_{2} \mathrm{O}_{4} /$ multi-walled carbon nanotubes hybrids: facile synthesis, characterization, and application to the treatment of dyeing wastewater, Ceramics International, 41 (2015) 11625-11631.

[14] X. Cui, X. Yang, X. Xian, L. Tian, H. Tang, Q. Liu, Insights into highly improved solar-driven photocatalytic oxygen evolution over integrated $\mathrm{Ag}_{3} \mathrm{PO}_{4} / \mathrm{MoS}_{2}$ heterostructures, Frontiers in chemistry, 6 (2018) 123.

[15] Y. Guo, P. Wang, J. Qian, Y. Ao, C. Wang, J. Hou, Phosphate group grafted twinned $\mathrm{BiPO}_{4}$ with significantly enhanced photocatalytic activity: Synergistic effect of improved charge separation efficiency and redox ability, Applied Catalysis B: Environmental, 234 (2018) 90-99.

[16] Z. Lu, G. Zhou, M. Song, D. Wang, P. Huo, W. Fan, H. Dong, H. Tang, F. Yan, G. Xing, Magnetic functional heterojunction reactors with $3 \mathrm{D}$ specific recognition for selective photocatalysis and synergistic photodegradation in binary antibiotic solutions, Journal of Materials Chemistry A, 7 (2019) 13986-14000.

[17] K.K. Gangu, S. Maddila, S.B. Jonnalagadda, A review on novel composites of MWCNTs mediated semiconducting materials as photocatalysts in water treatment, Science of the Total Environment, 646 (2019) 1398-1412.

[18] Z. Lu, Z. Yu, J. Dong, M. Song, Y. Liu, X. Liu, Z. Ma, H. Su, Y. Yan, P. Huo, Facile microwave synthesis of a Z-scheme imprinted $\mathrm{ZnFe}_{2} \mathrm{O}_{4} / \mathrm{Ag} / \mathrm{PEDOT}$ with the specific recognition ability towards improving photocatalytic activity and selectivity for tetracycline, Chemical Engineering Journal, 337 (2018) 228-241.

[19] Z. Lu, J. Peng, M. Song, Y. Liu, X. Liu, P. Huo, H. Dong, S. Yuan, Z. Ma, S. Han, Improved recyclability and selectivity of environment-friendly MFA-based heterojunction imprinted photocatalyst for secondary pollution free tetracycline orientation degradation, Chemical Engineering Journal, 360 (2019) 1262-1276.

[20] S. Liu, M. Zheng, R. Chen, Z. Wang, One-pot synthesis of an $\mathrm{AgBr} / \mathrm{ZnO}$ hierarchical structure with enhanced photocatalytic capacity, RSC Advances, 7 (2017) 31230-31238.

[21] M. Pelaez, P. Falaras, V. Likodimos, K. O'Shea, A. Armah, P.S. Dunlop, J.A. Byrne, D.D. Dionysiou, Use of selected scavengers for the determination of $\mathrm{NF}^{-\mathrm{TiO}_{2}}$ reactive oxygen species during the degradation of microcystin-LR under visible light irradiation, Journal of Molecular Catalysis A: Chemical, 425 (2016) 183-189. 
[22] S. Fang, M. Sun, Y. Zhou, Q. Liang, Z. Li, S. Xu, Solvothermal synthesis of CdS QDs/MWCNTs nanocomposites with high efficient photocatalytic activity under visible light irradiation, Journal of Alloys and Compounds, 656 (2016) 771-776.

[23] X. Song, Y. Li, Z. Wei, S. Ye, D.D. Dionysiou, Synthesis of $\mathrm{BiVO}_{4} / \mathrm{P} 25$ composites for the photocatalytic degradation of ethylene under visible light, Chemical Engineering Journal, 314 (2017) 443-452.

[24] N. Jamarun, S. Arief, Synthesis of $\mathrm{ZnO}-\mathrm{NiFe}_{2} \mathrm{O}_{4}$ Magnetic Nanocomposites by Simple Solvothermal Method for Photocatalytic Dye Degradation Under Solar Light, Oriental Journal of Chemistry, 32 (2016) 1411-1419.

[25] Q. Zhou, J.Z. Wen, P. Zhao, W.A. Anderson, Synthesis of vertically-aligned zinc oxide nanowires and their application as a photocatalyst, Nanomaterials, 7 (2017) 9.

[26] S.M. El-Sheikh, T.M. Khedr, G. Zhang, V. Vogiazi, A.A. Ismail, K. O’Shea, D.D. Dionysiou, Tailored synthesis of anatase-brookite heterojunction photocatalysts for degradation of cylindrospermopsin under UV-Vis light, Chemical Engineering Journal, 310 (2017) 428-436.

[27] Z. Jin, Q. Zhou, Y. Chen, P. Mao, H. Li, H. Liu, J. Wang, Y. Li, Graphdiyne: ZnO Nanocomposites for High-Performance UV Photodetectors, Advanced Materials, 28 (2016) 3697-3702.

[28] S. Sunitha, A.N. Rao, J. Karthikeyan, Synthesis of novel cobalt doped zinc oxide/carbon nano composite for the photocatalytic degradation of acid blue 113, Oriental Journal of Chemistry, 31 (2015) 107-112.

[29] Z. Lu, M. He, L. Yang, Z. Ma, L. Yang, D. Wang, Y. Yan, W. Shi, Y. Liu, Z. Hua, Selective photodegradation of 2-mercaptobenzothiazole by a novel imprinted $\mathrm{CoFe}_{2} \mathrm{O}_{4} / \mathrm{MWCNTs}$ photocatalyst, RSC Advances, 5 (2015) 47820-47829.

[30] H. Zhu, Y. Fu, R. Jiang, J. Yao, L. Liu, Y. Chen, L. Xiao, G. Zeng, Preparation, characterization and adsorption properties of chitosan modified magnetic graphitized multi-walled carbon nanotubes for highly effective removal of a carcinogenic dye from aqueous solution, Applied Surface Science, 285 (2013) 865-873.

[31] Y. Liu, W. Jiang, Y. Wang, X. Zhang, D. Song, F. Li, Synthesis of $\mathrm{Fe}_{3} \mathrm{O}_{4} / \mathrm{CNTs}$ magnetic nanocomposites at the liquid-liquid interface using oleate as surfactant and reactant, Journal of Magnetism and Magnetic Materials, 321 (2009) 408-412.

[32] A.A. Ensafi, A.R. Allafchian, Multiwall carbon nanotubes decorated with $\mathrm{NiFe}_{2} \mathrm{O}_{4}$ magnetic nanoparticles, a new catalyst for voltammetric determination of cefixime, Colloids and Surfaces B: Biointerfaces, 102 (2013) 687693.

[33] P. Xiong, Y. Fu, L. Wang, X. Wang, Multi-walled carbon nanotubes supported nickel ferrite: A magnetically recyclable photocatalyst with high photocatalytic activity on degradation of phenols, Chemical engineering journal, 195 (2012) 149-157.

[34] Y. Prabhu, B. Sreedhar, U. Pal, Achieving Enhanced Photocatalytic Activity of ZnO Supported on MWCNTs towards Degradation of Pollutants Under Visible Light, Materials Today: Proceedings, 8 (2019) 419-426.

[35] M. Sampaio, R. Bacsa, A. Benyounes, R. Axet, P. Serp, C.G. Silva, A. Silva, J.L. Faria, Synergistic effect between carbon nanomaterials and $\mathrm{ZnO}$ for photocatalytic water decontamination, Journal of Catalysis, 331 (2015) 172-180.

[36] M. Bagheri, N.R. Najafabadi, E. Borna, Removal of reactive blue 203 dye photocatalytic using ZnO nanoparticles stabilized on functionalized MWCNTs, Journal of King Saud University-Science, (2019).

[37] M. Nawaz, A. Shahzad, K. Tahir, J. Kim, M. Moztahida, J. Jang, M.B. Alam, S.-H. Lee, H.-Y. Jung, D.S. Lee, Photo-Fenton reaction for the degradation of sulfamethoxazole using a multi-walled carbon nanotube$\mathrm{NiFe}_{2} \mathrm{O}_{4}$ composite, Chemical Engineering Journal, 382 (2020) 123053.

[38] H.-Y. Zhu, R. Jiang, Y.-Q. Fu, R.-R. Li, J. Yao, S.-T. Jiang, Novel multifunctional $\mathrm{NiFe}_{2} \mathrm{O}_{4} / \mathrm{ZnO}$ hybrids for dye removal by adsorption, photocatalysis and magnetic separation, Applied surface science, 369 (2016) 1-10.

[39] N.R. Su, P. Lv, M. Li, X. Zhang, M. Li, J. Niu, Fabrication of $\mathrm{MgFe}_{2} \mathrm{O}_{4}-\mathrm{ZnO}$ heterojunction photocatalysts for application of organic pollutants, Materials Letters, 122 (2014) 201-204.

[40] K. Seffah, N. Bensacia, A. Skender, E. Flahaut, Synthesis and characterization of nano-magnetic material based on (carbon nanotubes/nickel ferrite): Application for the removal of methyl orange dye from contaminated water, algerian journal of environmental science and technology, 3 (2017) 45-53.

[41] J. Deng, X. Wen, Q. Wang, Solvothermal in situ synthesis of $\mathrm{Fe}_{3} \mathrm{O}_{4}$-multi-walled carbon nanotubes with enhanced heterogeneous Fenton-like activity, Materials Research Bulletin, 47 (2012) 3369-3376. 
[42] H. Zhu, R. Jiang, Y. Fu, Y. Guan, J. Yao, L. Xiao, G. Zeng, Effective photocatalytic decolorization of methyl orange utilizing $\mathrm{TiO}_{2} / \mathrm{ZnO} /$ chitosan nanocomposite films under simulated solar irradiation, Desalination, 286 (2012) 41-48.

[43] Y. Yu, C.Y. Jimmy, C.-Y. Chan, Y.-K. Che, J.-C. Zhao, L. Ding, W.-K. Ge, P.-K. Wong, Enhancement of adsorption and photocatalytic activity of $\mathrm{TiO}_{2}$ by using carbon nanotubes for the treatment of azo dye, Applied Catalysis B: Environmental, 61 (2005) 1-11.

[44] X.-j. FAN, L. Xin, Preparation and magnetic property of multiwalled carbon nanotubes decorated by $\mathrm{Fe}_{3} \mathrm{O}_{4}$ nanoparticles, New Carbon Materials, 27 (2012) 111-116.

[45] X. Hou, J. Feng, X. Liu, Y. Ren, Z. Fan, T. Wei, J. Meng, M. Zhang, Synthesis of 3D porous ferromagnetic $\mathrm{NiFe}_{2} \mathrm{O}_{4}$ and using as novel adsorbent to treat wastewater, Journal of colloid and interface science, 362 (2011) 477-485.

[46] K.C. Verma, V.P. Singh, M. Ram, J. Shah, R. Kotnala, Structural, microstructural and magnetic properties of $\mathrm{NiFe}_{2} \mathrm{O}_{4}, \mathrm{CoFe}_{2} \mathrm{O}_{4}$ and $\mathrm{MnFe}_{2} \mathrm{O}_{4}$ nanoferrite thin films, Journal of magnetism and magnetic materials, 323 (2011) 3271-3275.

[47] M. Sun, T. Li, Z. Zhang, N. Wang, A. Xie, X. Lv, Y. Wang, F. Wu, M. Wang, Natural biological template for $\mathrm{ZnO}$ nanoparticle growth and photocatalytic dye degradation under visible light, RSC Advances, 5 (2015) 84406-84409.

[48] M. Mozaffari, J. Amighian, E. Darsheshdar, Magnetic and structural studies of nickel-substituted cobalt ferrite nanoparticles, synthesized by the sol-gel method, Journal of magnetism and magnetic materials, 350 (2014) 19-22.

[49] N. Srinivasan, Y. Shiga, D. Atarashi, E. Sakai, M. Miyauchi, A PEDOT-coated quantum dot as efficient visible light harvester for photocatalytic hydrogen production, Applied Catalysis B: Environmental, 179 (2015) 113-121.

[50] S. Arora, M.L. Singla, P. Kapoor, Evidence for monoalkoxide species on the surface of palladium nanoparticles synthesized in ethylene glycol, Materials Chemistry and Physics, 114 (2009) 107-112.

[51] J. Zhang, H. Zou, Q. Qing, Y. Yang, Q. Li, Z. Liu, X. Guo, Z. Du, Effect of chemical oxidation on the structure of single-walled carbon nanotubes, The Journal of Physical Chemistry B, 107 (2003) 3712-3718.

[52] Z. Li, G. Che, W. Jiang, L. Liu, H. Wang, Visible-light-driven CQDs@ MIL-125 (Ti) nanocomposite photocatalyst with enhanced photocatalytic activity for the degradation of tetracycline, RSC Advances, 9 (2019) 33238-33245.

[53] Y. Zhan, R. Zhao, Y. Lei, F. Meng, J. Zhong, X. Liu, A novel carbon nanotubes $/ \mathrm{Fe}_{3} \mathrm{O}_{4}$ inorganic hybrid material: Synthesis, characterization and microwave electromagnetic properties, Journal of magnetism and magnetic materials, 323 (2011) 1006-1010.

[54] I. Vergili, Z.B. Gönder, Y. Kaya, G. Gürdağ, S. Çavuş, Lead removal from battery wastewater using synthesized poly (ethyleneglycol dimethacrylate-methacrylic acid) gel bead and poly (methacrylic acid) hydrogel, Polymer Bulletin, 74 (2017) 2605-2624.

[55] J. Jiang, L.-H. Ai, L.-C. Li, H. Liu, Facile fabrication and characterization of $\mathrm{NiFe}_{2} \mathrm{O}_{4} / \mathrm{ZnO}$ hybrid nanoparticles, Journal of alloys and compounds, 484 (2009) 69-72.

[56] R. Waldron, Infrared spectra of ferrites, Physical review, 99 (1955) 1727.

[57] T. Arfin, S.N. Rangari, Graphene oxide-ZnO nanocomposite modified electrode for the detection of phenol, Analytical methods, 10 (2018) 347-358.

[58] M. Hashim, S. Kumar, S.E. Shirsath, R. Kotnala, J. Shah, R. Kumar, Synthesis and characterizations of Ni ${ }^{2+}$ substituted cobalt ferrite nanoparticles, Materials Chemistry and Physics, 139 (2013) 364-374.

[59] R. Mishra, S. Tripathy, D. Sinha, K. Dwivedi, S. Ghosh, D. Khathing, M. Müller, D. Fink, W. Chung, Optical and electrical properties of some electron and proton irradiated polymers, Nuclear Instruments and Methods in Physics Research Section B: Beam Interactions with Materials and Atoms, 168 (2000) 59-64.

[60] E. Casbeer, V.K. Sharma, X.-Z. Li, Synthesis and photocatalytic activity of ferrites under visible light: a review, Separation and Purification Technology, 87 (2012) 1-14.

[61] H. Derikvandi, A. Nezamzadeh-Ejhieh, Synergistic effect of pn heterojunction, supporting and zeolite nanoparticles in enhanced photocatalytic activity of $\mathrm{NiO}$ and $\mathrm{SnO}_{2}$, Journal of colloid and interface science, 490 (2017) 314-327. 
[62] A. Shirzadi, A. Nezamzadeh-Ejhieh, Enhanced photocatalytic activity of supported CuO-ZnO semiconductors towards the photodegradation of mefenamic acid aqueous solution as a semi real sample, Journal of Molecular Catalysis A: Chemical, 411 (2016) 222-229.

[63] L. Lin, J. Huang, X. Li, M.A. Abass, S. Zhang, Effective surface disorder engineering of metal oxide nanocrystals for improved photocatalysis, Applied Catalysis B: Environmental, 203 (2017) 615-624.

[64] P. Chand, S. Vaish, P. Kumar, Structural, optical and dielectric properties of transition metal $\left(\mathrm{MFe}_{2} \mathrm{O}_{4} ; \mathrm{M}=\right.$ $\mathrm{Co}, \mathrm{Ni}$ and Zn) nanoferrites, Physica B: Condensed Matter, 524 (2017) 53-63.

[65] S. Joshi, M. Kumar, S. Chhoker, G. Srivastava, M. Jewariya, V. Singh, Structural, magnetic, dielectric and optical properties of nickel ferrite nanoparticles synthesized by co-precipitation method, Journal of Molecular Structure, 1076 (2014) 55-62.

[66] R.H. Kodama, Magnetic nanoparticles, Journal of Magnetism and Magnetic Materials, 200 (1999) 359-372.

[67] J.Z. Msomi, Synthesis, structural and magnetic properties of bulk and nanosized $(\mathrm{Zn}, \mathrm{Cd}, \mathrm{Cu})_{0.5} \mathrm{Ni}_{0.5} \mathrm{Fe}_{2} \mathrm{O}_{4}$ and $\mathrm{NiFe}_{2} \mathrm{O}_{4}$ ferrites, in, 2010.

[68] M. Hoppe, Magnetic, structural, and electronic properties of $\mathrm{NiFe}_{2} \mathrm{O}_{4}$ ultrathin films, Reihe Schlüsseltechnologien / Key Technologies 2015.

[69] R.J. Tilley, Crystals and crystal structures, John Wiley \& Sons, 2006.

[70] A.M. Gismelseed, K. Mohammed, H. Widatallah, A. Al-Rawas, M. Elzain, A. Yousif, Structure and magnetic properties of the $\mathrm{Zn}_{\mathrm{x}} \mathrm{Mg}_{1-\mathrm{x}} \mathrm{Fe}_{2} \mathrm{O}_{4}$ ferrites, in: Journal of Physics: Conference Series, IOP Publishing, 2010 , pp. 012138.

[71] M. Rashad, D. Rayan, A. Turky, M. Hessien, Effect of $\mathrm{Co}^{2+}$ and $\mathrm{Y}^{3+}$ ions insertion on the microstructure development and magnetic properties of $\mathrm{Ni}_{0.5} \mathrm{Zn}_{0.5} \mathrm{Fe}_{2} \mathrm{O}_{4}$ powders synthesized using co-precipitation method, Journal of Magnetism and Magnetic Materials, 374 (2015) 359-366.

[72] A. Globus, H. Pascard, V. Cagan, Distance between magnetic ions and fundamental properties in ferrites, Le Journal de Physique Colloques, 38 (1977) C1-163-C161-168.

[73] E. Mosiniewicz-Szablewska, A.R. Clavijo, A.P. Castilho, L.G. Paterno, M.A. Pereira-da-Silva, J. Więckowski, M.A. Soler, P.C. Morais, Magnetic studies of layer-by-layer assembled polyvinyl alcohol/iron oxide nanofilms, Physical Chemistry Chemical Physics, 20 (2018) 26696-26709.

[74] J.-H. Nam, S.J. Park, W.K. Kim, Microstructure and magnetic properties of nanostructured NiZnCu ferrite powders synthesized by sol-gel process, IEEE transactions on magnetics, 39 (2003) 3139-3141.

[75] J. Duque, E. Souza, C. Meneses, L. Kubota, Magnetic properties of $\mathrm{NiFe}_{2} \mathrm{O}_{4}$ nanoparticles produced by a new chemical method, Physica B: Condensed Matter, 398 (2007) 287-290.

[76] A.H. Lu, E.e.L. Salabas, F. Schüth, Magnetic nanoparticles: synthesis, protection, functionalization, and application, Angewandte Chemie International Edition, 46 (2007) 1222-1244.

[77] S.P. Gubin, Magnetic nanoparticles, John Wiley \& Sons, 2009.

[78] G.-y. Li, Y.-r. Jiang, K.-l. Huang, P. Ding, J. Chen, Preparation and properties of magnetic $\mathrm{Fe}_{3} \mathrm{O}_{4}-\mathrm{chitosan}$ nanoparticles, Journal of alloys and compounds, 466 (2008) 451-456.

[79] J. Qu, C. Luo, Q. Cong, Synthesis of carbon nanotube/ZnO nanocomposites using absorbent cotton and their photocatalytic activity, Micro \& Nano Letters, 7 (2012) 1064-1068.

[80] C.-H. Chen, Y.-H. Liang, W.-D. Zhang, $\mathrm{ZnFe}_{2} \mathrm{O}_{4} / \mathrm{MWCNTs}$ composite with enhanced photocatalytic activity under visible-light irradiation, Journal of Alloys and Compounds, 501 (2010) 168-172.

[81] S. Iftikhar, M.F. Warsi, S. Haider, S. Musaddiq, I. Shakir, M. Shahid, The impact of carbon nanotubes on the optical, electrical, and magnetic parameters of $\mathrm{Ni}^{2+}$ and $\mathrm{Co}^{2+}$ based spinel ferrites, Ceramics International, 45 (2019) 21150-21161.

[82] F. Hosseini, A. Kasaeian, F. Pourfayaz, M. Sheikhpour, D. Wen, Novel ZnO-Ag/MWCNT nanocomposite for the photocatalytic degradation of phenol, Materials Science in Semiconductor Processing, 83 (2018) 175-185.

[83] N. Roozban, S. Abbasi, M. Ghazizadeh, Statistical analysis of the photocatalytic activity of decorated multiwalled carbon nanotubes with $\mathrm{ZnO}$ nanoparticles, Journal of Materials Science: Materials in Electronics, 28 (2017) 6047-6055.

[84] M. Elias, M.K. Amin, S.H. Firoz, M.A. Hossain, S. Akter, M.A. Hossain, M.N. Uddin, I.A. Siddiquey, Microwave-assisted synthesis of Ce-doped $\mathrm{ZnO} / \mathrm{CNT}$ composite with enhanced photo-catalytic activity, Ceramics International, 43 (2017) 84-91. 
[85] D. Chaudhary, S. Singh, V. Vankar, N. Khare, ZnO nanoparticles decorated multi-walled carbon nanotubes for enhanced photocatalytic and photoelectrochemical water splitting, Journal of Photochemistry and Photobiology A: Chemistry, 351 (2018) 154-161.

[86] Z. Lu, F. Chen, M. He, M. Song, Z. Ma, W. Shi, Y. Yan, J. Lan, F. Li, P. Xiao, Microwave synthesis of a novel magnetic imprinted $\mathrm{TiO}_{2}$ photocatalyst with excellent transparency for selective photodegradation of enrofloxacin hydrochloride residues solution, Chemical Engineering Journal, 249 (2014) 15-26.

[87] S. Xun, W. Zhu, Y. Chang, H. Li, M. Zhang, W. Jiang, D. Zheng, Y. Qin, H. Li, Synthesis of supported $\mathrm{SiW}_{12} \mathrm{O}_{40}$-based ionic liquid catalyst induced solvent-free oxidative deep-desulfurization of fuels, Chemical Engineering Journal, 288 (2016) 608-617.

[88] Q. Liu, J. Shen, X. Yang, T. Zhang, H. Tang, 3D reduced graphene oxide aerogel-mediated Z-scheme photocatalytic system for highly efficient solar-driven water oxidation and removal of antibiotics, Applied Catalysis B: Environmental, 232 (2018) 562-573.

[89] H. Yu, Y. Huang, D. Gao, P. Wang, H. Tang, Improved $\mathrm{H}_{2}$-generation performance of Pt/CdS photocatalyst by a dual-function $\mathrm{TiO}_{2}$ mediator for effective electron transfer and hole blocking, Ceramics International, 45 (2019) 9807-9813. 